\title{
PASSENGER RECOVERY AFTER AN AIRPORT CLOSURE AT TOURIST DESTINATIONS: A CASE STUDY OF PALMA DE MALLORCA AIRPORT
}

\author{
Augusto Voltes-Dorta (corresponding author) \\ University of Edinburgh Business School \\ Management Science and Business Economics Group \\ EH8 9JS Edinburgh, United Kingdom \\ avoltes@,becarios.ulpgc.es \\ Héctor Rodríguez-Déniz \\ Division of Statistics and Machine Learning \\ Department of Computer and Information Science, \\ Linköping University, Linköping, Sweden \\ hrodriguez@,becarios.ulpgc.es \\ Pere Suau-Sanchez \\ Cranfield University \\ Centre for Air Transport Management \\ MK43 0TR, Bedfordshire, United Kingdom \\ p.suausanchez@cranfield.ac.uk
}

\begin{abstract}
In the context of increased concern about the resilience of critical transport infrastructure to external events and the impact of such events on local tourism industries, this paper analyzes the ability of tourism-oriented airports to relocate departing passengers in the event of an unexpected airport closure. A case study of Palma de Mallorca Airport is presented. Using an MIDT dataset on passenger itineraries in August 2014, several closure scenarios are simulated, and disrupted passengers are relocated to minimum-delay itineraries. Aggregate delays and relocation rates are used to assess the impact of each scenario, with a particular focus on UK and Germany markets. The results provide useful benchmarks for the development of policies aimed at minimizing the impact on stranded tourists, such as allowing for passenger connections, establishing a protocol for interline cooperation, and improving intermodal transfers. These measures will help mitigate the negative impacts on airline loyalty and destination image.
\end{abstract}

Keywords: Tourist airports; crisis management; passenger recovery; resilience; destination image.

\section{INTRODUCTION}

In recent years, a number of events have challenged the robustness of air transport services worldwide. These events negatively affect both passengers, particularly those departing or returning from their holidays at major tourist destinations, and airlines, which have a statutory responsibility to assist their disrupted passengers. The nature of each disruptive event varies, though most events are related to those most widely addressed in the literature on post-crisis recovery at tourism destinations, i.e., weather events and terrorist attacks (Mair et al., 2016). In 2010, the Volcanic Ash Cloud led to thousands of cancelled flights, millions of stranded tourists across Europe, and massive economic impacts (Mazzocchi et al., 2010). On a smaller scale, a volcanic eruption led to the closure of Bali International airport in November 2015, with the expected impact on tourists returning from holidays (BBC, 2015a). The closures of both London and Gatwick airports for several days in December 2010 due to heavy snowfall also left thousands of tourists trapped (BBC, 2010). In addition to weather conditions, industrial actions are also responsible for massive flight cancellations, particularly in periods of strong holiday demand: In late 2009, the entire Spanish airspace had to be closed due to a nationwide strike of air traffic controllers (ATC) at the beginning of the Constitution/Immaculate Conception holiday (El País, 2009). In March 2016, the French ATC strike affected European holidaymakers during the Easter period (BBC, 2016), continuing a trend from previous years. Between 2015 and 2016, several strikes (primarily 
ATC and ground handling) also occurred in Italy, Spain, and Greece, causing many flight cancellations, as reported by the websites of Europe's major low-cost carriers (LCCs). An industrial action was also an underlying cause of the collapse of Vueling operations at Barcelona airport in July 2016. In this case, however, the primary factor, as concluded by the Spanish Government, was the lack of resilient planning of summer operations by the low-cost carrier, which compromised its ability to adapt to minor disruptions (El País, 2016).

Furthermore, it is worth mentioning the threat of terrorism, which has also affected airports directly. According to the Global Terrorism Database compiled by START (2016), 75 terrorist attacks specifically targeted European airports between 1970 and 2015, 83\% of which were bombings/explosions. Twenty-eight of these airport attacks $(37.3 \%)$ occurred during the summer months. The most affected airports are located in the UK (primarily London and Belfast), France (Paris), Italy (Rome), Spain (Madrid), and Turkey (Istanbul), which together accounted for 39 attacks (52\% of the attacks in the last 45 years). This trend continued during the first nine months of 2016, when two major attacks in Europe occurred. The bombing of a passenger terminal at Brussels International Airport on March $22^{\text {nd }}$ led to a full closure for passenger flights that lasted for 12 days, affecting many tourists, after which the airport opened on a limited basis (CNN, 2016). Istanbul Ataturk Airport was the target of a very similar bombing attack on the evening of June $28^{\text {th }}$. However, in this case, the airport closed only overnight and was operating by the next morning (NYT, 2016). Terrorist attacks at non-European airports can also affect European holiday travelers. For example, the presumed bombing of a Russian flight departing from Sharm el-Sheikh Airport (Egypt) in November 2015 led to many flight cancellations due to increased security measures that left more than a thousand UK tourists stranded (BBC, 2015b) and caused substantial immediate damage to the tourism industry in the city (Colliers, 2016). In the future, the predicted rates of growth in air transport demand (ICAO, 2013) and the current geopolitical instability in regions that attract substantial tourism activity (e.g., the Mediterranean) could reduce the ability to cope with such disturbances and put additional pressure on airport and airline managers as well as public authorities in tourist destinations.

The existing tourism literature (see, e.g., Mair et al., 2016) provides little insight into the role of air transportation agents in crisis management at tourism destinations, particularly regarding the recovery of departing tourists stranded due to massive flight cancellations. Previous studies in a broader tourism context, however, have established the negative impact of large-scale disruptions on destination image. The impact is particularly severe if it generates negative word-of-mouth (Lehto et al., 2008), if the tourists are relatively close to the source of the disruption (Walters and Clulow, 2010), and if there is some attribution of responsibility by the tourists to a local authority or organization (Breitsohl and Garrod, 2016). We argue that these characteristics are present in disruptive events that directly involve air transport services. Therefore, the issue of passenger recovery at tourism-oriented airports is bound to be relevant not only from a purely service-recovery perspective (airports and airlines) but also from the perspective of protecting the destination image (tourism authorities). The literature also highlights the importance of planning and preparedness for improving the outcome of crisis management strategies in tourism destinations (Ritchie, 2008), bringing the concepts of resilience, speed of recovery, and cooperation into play (Scott and Laws, 2008). At this point, however, the tourism literature becomes mainly qualitative and discursive, with some authors (e.g., Mair et al., 2016) recommending the production of more quantitative research.

To that end, it is worth mentioning that there is a decent body of transport literature on the structure of airline networks and their implications in terms of resilience to airport failures or the closure of air corridors (Lordan et al., 2014a). Building on these papers, we seek the 
opportunity to adapt a quantitative transport methodology to the subject of tourism. To the best of our knowledge, there is no quantitative study that focuses on passenger service recovery at tourism-oriented airports in the transport or tourism literatures. We argue that this type of airport presents a set of characteristics that warrant differentiated treatment, such as a focus on origin-destination traffic, the prevalence of insular or otherwise isolated locations, strong seasonality (Dobruszkes, 2013), or the dominance of LCCs. These carriers have a strong focus on cost-cutting measures (Doganis, 2006), and their service failures typically result in more complaints in comparison to full-service carriers (Bamford and Xystouri, 2005; Dobruszkes, 2006). These characteristics can hamper the ability of tourism-oriented airports to relocate stranded passengers in the event of a major disruption and, therefore, should be analyzed within a context of tourism crisis management, alongside any policies aimed to improve the speed of recovery, including the issue of multi-party cooperation highlighted in the literature.

We observe a disconnection between the analyses provided by the transport literature and the actual impact of airline or airport disruptions on the final users (i.e., the passengers/tourists who experience travel delays). Only a few of the available studies on air transport vulnerability and resilience consider the important aspect of how airlines relocate disrupted passengers, and to the best of our knowledge, no paper has taken into account the full passenger itineraries by employing air passenger demand data, as we do in this paper. Knowing the original passenger itineraries allows us to simulate an airline recovery process (i.e., rescheduling the stranded passengers) in the event of an airport closure. The use of demand data also allows us to disaggregate the impact across geographical markets, which is also a novel contribution to the literature. The relevance of this disaggregation can be understood by contrasting the literature on airline service recovery - which establishes the importance of "fairness" in that process (Akamavi et al., 2015; Nibkin et al., 2015) — with the experience of UK passengers stranded at Sharm el-Sheikh Airport in November 2015. These passengers faced longer delays than holidaymakers from other countries. While these differences were linked to increased security measures from UK authorities, it illustrates a situation in which a perceived "unfairness" in service recovery leads to passenger dissatisfaction (The Guardian, 2015) and negative impacts for the airline and the local tourism industry.

In this context, the objective of the present paper is to analyze the ability of tourism-oriented airports to relocate departing passengers in the event of an unexpected airport closure. A case study of Palma de Mallorca Airport (PMI), the busiest tourism-oriented island airport in Europe, is presented. PMI is chosen due to its large number of passenger departures and the lack of alternative modes of transportation in the event on an airport closure. Moreover, the case study provides enough variability on airline types and geographical markets for a more detailed discussion of the results. Using an MIDT dataset on passenger itineraries that includes flights in August 2014, several closure scenarios are simulated, and disrupted passengers are sequentially relocated to minimum-delay itineraries where seat capacity is available. Average departure delays and non-relocation rates are used, along with other indicators, to assess the damage caused by each closure scenario, with a particular focus on the impact on UK and Germany markets. An econometric regression reveals the existence of airline and market-specific effects on the quality of passenger relocation at Palma de Mallorca International Airport. The analysis of the results focuses on the development of policies aimed at minimizing the impact on stranded tourists, such as allowing for passenger connections, establishing a protocol for interline cooperation, or improving intermodal access. All these measures are expected to play a role in mitigating the impact of the airport closure on airline loyalty and the destination image of the affected country or region. 
The remainder of this paper is structured as follows: Section 2 summarizes the European regulations on passengers' rights in the event of cancellations and delays. Section 3 provides a literature review on all subjects relevant to this paper and discusses our contribution. Section 4 introduces the case study and describes the dataset and methodology. Section 5 presents the results and discusses their main implications. Finally, Section 6 summarizes our findings, addresses the limitations of our model, and proposes new paths for future research.

\section{REGULATORY BACKGROUND}

European regulations - i.e., European Commission (EC) No. 261/2004 — grant airline passengers a number of rights in the event of flight cancellation or delay (see EC, 2008). These include the rights of care, rerouting, reimbursement, and compensation. The regulations recognize three different thresholds of departure delay, depending on the travel distance, that trigger a duty of care by the airline. Type 1 trips are those under $1,500 \mathrm{~km}$, for which the threshold is two hours; type 2 trips are those between 1,500 km and 3,500 km (and all remaining intra-EU flights), for which the threshold is three hours; and type 3 trips are the remaining ones (longer than 3,500 km), for which the threshold is four hours. This classification refers to the great circle distance between the affected passenger's location (e.g., point of departure of the cancelled flight) and the last destination at which the cancellation will delay the passenger's scheduled arrival. Airlines should provide passengers with meals and refreshments, hotel accommodations (when overnight stays are needed), airport transfers, and appropriate means of communication (e.g., phone, email, and/or fax). Delays longer than five hours also allow passengers to cancel their reservation and be reimbursed in full "for the parts of the journey not made, and for the parts already made if the flight is no longer serving any purpose in relation to the passenger's original travel plan". The duty of care of an air carrier stops when the reservation is cancelled.

In the event of a flight cancellation, passengers are entitled to all of the above, but they can also be offered a new travel itinerary (rerouting) — under "comparable transport conditions" - to their final destination "at the earliest convenience" and "subject to availability of seats". According to the EC, "re-routing does not necessarily need to be operated by the airline the passenger booked with", and "re-routing alternatives can be proposed by other means of transport, such as train, taxi or bus, if the distance to be covered is appropriate for such transport modes" (EC, 2008). Finally, passengers on cancelled flights are also entitled to compensation under certain conditions, such as when the cancellation is not caused by extraordinary circumstances beyond the airline's control (e.g., safety and security, weather, industrial actions, or airport facilities). The airline is not liable to pay compensation when 1) passengers are given notice more than two weeks before their flight or 2) they are given notice between two weeks and seven days before their flight and offered rerouting that departs no more than two hours before, and arrives no less than four hours after, the original flight (one hour before and two hours after if less than a week's notice is given). The amount of compensation is EUR 250, EUR 400, and EUR 600 for type 1, type 2, and type 3 trips, respectively, as defined above. These amounts are reduced by $50 \%$ if the airline offers a suitable rerouting with a maximum arrival delay for type 1, type 2, and type 3 trips, analogous to the ones at the beginning of this section.

\section{LITERATURE REVIEW AND CONTRIBUTION}

Our contribution is thematically framed within the tourism literature, particularly in the areas of post-crisis recovery and destination image. From a methodological perspective, however, it builds on concepts from the transport literature, particularly papers that analyze the resilience of transport networks, upon which we develop a new methodology to measure passenger delays and relocation rates and to identify airline- and market-specific effects. 


\subsection{Tourism literature}

A recent survey of the published research on post-crisis recovery strategies for tourist destinations (Mair et al., 2016) does not feature any research with a primary focus on the role of transportation agents, airports, or airlines in that process. This is at odds with the definition of a tourism product (Gunn, 1998) as a complex experience where tourists use multiple services during the course of their visit (including transportation, accommodation, and attraction services). The role of transportation services as a factor in the creation a "destination product" has been empirically established since Mo et al. (1993), while the impact of transportation infrastructure on international tourism growth has also been established by studies such as Khadaroo and Seetanah (2008). In that regard, it is common for airport managers to refer to the key role of airports as visitors' first and last impressions of a particular city or country (Heathrow Airport, 2014). Several studies also note the close link between airport service quality and destination image, as services such as check-in (Rendeiro, 2006) or food and beverage (Del Chiappa et al., 2016) are an integral part of the tourism experience. Therefore, we conclude that the key role that transportation agents, including airports and airlines, must play in crisis recovery at tourist destinations has been neglected by the tourism crisis management literature.

The relevance of this gap is accentuated by the fact that the same literature indicates several factors that are harmful to destination image and are present in disruptive events involving air transport. First, a link between the destination image and brand image of the organizations and businesses involved is established by Niininen and Gatsou (2008). In this regard, Lehto et al. (2008) document the damage to the destination image after the 2004 Indian Ocean Tsunami caused by negative word-of-mouth about seaside destinations in the affected areas. Arguably, this process applies to air transport disruptions: The generation of word-of-mouth is a typical outcome of airline service recovery interactions, as indicated by Weber and Sparks (2004). Any negative impact on the airline's brand image can also have an impact on the image of the affected destination. This effect is potentiated in the case of airport service recovery interactions because the name of the airport typically includes the name of the city where the disruption took place. The second factor is the concept of proximity, explored by Walters and Clulow (2010), which has been shown to affect tourists' perceptions of a disruptive event. In the case of air transport disruptions, this "proximity" is inferred from the role of tourists as the users of the service that has been suspended, who now depend on the recovery of the service for the provision of their basic needs (i.e., food and accommodation). Third, Breitsohl and Garrod (2016) reflect on the concepts of severity and responsibility attribution in a destination image context, with a focus on i) the amount of damage generated by the disruptive event, ii) the cognitive association of the cause of an incident with a particular entity, and iii) the perceived likelihood of that entity experiencing any negative effects from its disrupting decision. The stronger these three effects, the greater the damage to the destination image. The connection to air transport is supported by the airline service recovery literature, which has established the link between the "controllability" of a disruption event and passenger trust and loyalty towards an airline. Controllability refers to customers' evaluation of whether the cause of the failure was uncontrollable or controllable by the service provider (Nibkin et al., 2015). Again, we submit that this effect is present in air transport disruptions, particularly those associated with large-scale industrial actions, such as ATC strikes. Thus, by focusing on air transport disruptions, our contribution is relevant at the first level from the perspective of destination image recovery.

At the second level, we also contribute to the literature on tourism service recovery, which already includes a few papers focusing on airline passengers (see, e.g., Cheng et al., 2008; Lindenmeier and Tscheulin, 2008; Akamavi et al., 2015; and Nibkin et al., 2015). A recurring 
theme in these publications is the idea of "fairness", linked to both i) the perception of whether the extent of the recovery effort is sufficient to compensate passengers for their trouble and ii) the perception that the airline prioritized ethical principles, rather than profit maximization, in its recovery decision-making process. Fairness is identified as a key driver of airport service quality by Wattanacharoensil et al. (2015). Furthermore, it is worth remembering that regardless of the cause of the disruption, passengers are always instructed to contact their respective airline. Therefore, even if the airlines are not directly responsible (e.g., weather, terrorism), a sentiment of "unfairness" towards the airlines can arise if passengers perceive that the commitment to and quality of recovery efforts are not in line with the extent of the damage caused to them. Whereas these previous studies are mainly based on questionnaire data on passenger perceptions, we are able to contribute to the airline service recovery literature in a different way, i.e., with a comparative analysis of the quality of passenger relocation across different airlines and geographical markets. The airline dimension of this analysis is highly relevant. The strong focus on cost-cutting measures from LCCs (Doganis, 2006) can drive feelings of unfairness among stranded passengers, particularly in comparison with the recovery service offered by full-service airlines. The country-level dimension of this analysis is also a novel contribution, motivated by the November 2015 experience of UK passengers at Sharm el-Sheikh Airport and their differentiated treatment in comparison with passengers departing to other countries.

Finally, the tourism literature also highlights the importance of planning and preparedness in improving the outcome of crisis management strategies (Ritchie, 2008), bringing the concepts of "resilience" and speed of recovery into play (Scott and Laws, 2008), as well as the need for multi-party cooperation in resilience planning (Xu and Grunewald, 2009). None of these topics has been covered in a case study on a tourism-oriented airport. Authors such as Ciocco and Michael (2007) note the difficulties that individual operators face in rebuilding their market shares in the absence of mutual collaboration. This issue is bound to be relevant in relation to LCC service recovery at tourist airports because these types of airlines are not typically part of an alliance and thus do not have immediate airline partners to reach in the event of a disruption.

The tourism literature becomes mainly discursive in relation to these topics, with Mair et al. (2016) recommending the production of more quantitative research. To that end, we aim to develop a quantitative model to measure the effectiveness of several strategies at the time of improving the speed of recovery and minimizing the impact on stranded tourists in the event of an airport closure. Based on the conclusions of the crisis management and service recovery literature, we will address the issues of airline cooperation and fairness by comparing the outcomes (in terms of travel delays and rates of relocation) of the airline recovery process under different cooperation scenarios and across airlines and geographical markets.

\subsection{Transport literature}

The literature on transport resilience and vulnerability offers a relevant body of knowledge to operationalize the measurements needed to achieve the contributions stated in the previous section. Rose (2007) defines resilience as the ability of a system to maintain functionality when disrupted, with a particular focus on the speed at which the system returns to normal. Vulnerability is defined by Berdica (2002) as the "susceptibility of a system to experience disruptions that can affect its functionality". When referring to a transportation network, functionality is commonly related to the possibility of using any node or link of the network during a given period (Jenelius et al., 2006). Authors such as Berdica (2002) and D'Este and Taylor (2003) argue that measuring the magnitude of the consequences associated with a service disruption should be the primary focus of vulnerability studies. 
Mattsson and Jenelius (2015) describe two main approaches to measuring the vulnerability of transport networks: a) topological vulnerability and b) system-based vulnerability. In the topological vulnerability approach, the network is represented as an abstract graph, and the system damage is measured by the changes in network topology after a disruption affects one or more nodes or links. This approach uses only supply data on available infrastructure and service frequencies. In the system-based vulnerability approach, the network graph is complemented with information on actual or predicted traffic flows, and the interaction between supply and demand under disruptions is modelled, for example, with a user rerouting algorithm. Examples of this system-based approach are found in Jenelius et al. (2006), De los Santos et al. (2012), or Rodríguez-Núñez and García-Palomares (2014), where road and rail network vulnerability under a variety of disrupting scenarios is measured by the total delays experienced by users, who need to alter their original itineraries, and by the amount of unsatisfied demand. This second approach is the one we prefer for our case study. The reason is that it allows us to obtain a more detailed measurement of the consequences for stranded tourists in the event of an airport closure, to evaluate the performance of airlines in meeting the regulatory requirements of rerouting passengers in "comparable transport conditions" and to discuss the potential costs they incur.

Recent years have witnessed a growing interest in measuring the damage caused by the removal of nodes (i.e., airport closures) and/or links (i.e., air corridors) to determine the vulnerability of an air transport network to these events. The purely topological approach to assessing this damage does not explicitly take into account the need to redistribute the disrupted traffic. Nonetheless, many interesting conclusions can be obtained. Lordan et al. (2014b) model the global airport network and develop a measure of the damage produced by both random failures and targeted attacks based on the number of disconnected airports that result from them. Janic (2015) also relies on disconnected flights as a measure of network damage and concludes that larger airports (i.e., Atlanta in the case of 2012 Hurricane Sandy) tend to be the most critical. Lordan et al. (2015) analyze the resilience of the global airline alliance networks. They conclude that Star Alliance is the most resilient because its network has a more balanced distribution of important airports, in contrast with the dominance of few large hubs in the networks of Oneworld and SkyTeam. Finally, Lordan et al. (2016) examine the topological resilience of individual airline networks, establishing that the point-to-point flight networks of LCCs are more robust than the hub-and-spoke structures of traditional carriers. This is aligned with the established notion that as network concentration around pivotal nodes increases, so does the network's vulnerability, mainly because of the lack of structural redundancies that support the recovery of traffic flows via alternative routings (Zhang et al., 2015).

A system-based approach to assessing network vulnerability incorporates information on passenger flows to simulate how passengers are relocated after a disruption. The costs of airline disruptions for airlines and passengers have been measured by many studies that employ both monetary and non-monetary indicators (e.g., Schavell, 2000; Allan et al., 2001; Schaefer and Millner, 2001; Janic, 2005; Kohl et al., 2007; Janic, 2015). The most common non-monetary cost measures are the number of passengers affected (missed connections and cancellations), the proportion of those successfully relocated within a recovery window, and the total delay experienced, measured by the difference between the original and rescheduled itineraries (Bratu and Barnhart, 2006). We implement these measures of passenger disruption into our case study.

In simulating the airline recovery process, there is a need to replicate the challenges arising from irregular airline operations, with a particular focus on the recovery of aircraft, crews, and passengers in an optimal (i.e., cost-minimizing) fashion. The operating carrier typically 
takes responsibility for this process on the day of the disruption. As noted by Barnhart (2009), there are a number of strategies that airlines use to that end, including delaying and cancelling flights, reassigning aircraft or crews to different routes, and relocating disrupted passengers. These adjustments are subject to a number of restrictions, including crew work rules, maintenance schedules, aircraft and passenger positioning, and the inherent competitive pressures from other airlines operating at the same airport, to which dissatisfied passengers may switch. Thus, one can argue that robust operations can be a source of competitive advantage for airlines. However, the operating carrier may collaborate with other airlines during the recovery. If a ticket is sold as a codeshare, the disruption procedures are carried out through a specific annex within the agreement. Other procedures are carried out through agreements linked to alliance membership. According to EC (2007), most airlines will reach out to help a customer of another member airline if necessary. The importance of interline cooperation in improving the quality of airline recovery is noted by authors such as Wang (2007) - who looks at the effects of shared airline capacity on reducing passenger delay and by organizations such as AIAA (2015).

There is a decent body of operations research literature devoted to providing efficient methods to solve these optimization problems under different scenarios (e.g., Yan and Lin, 1997; Lettovsky et al., 2000; Abdelghany et al. 2008; Bratu and Barnhart, 2006; Petersen et al., 2012, and Maher, 2015). However, Kohl et al. (2007) note the lack of studies featuring interline cooperation for passenger recovery. The available works address single-airline cases (in isolation from larger-scale air transport networks) and aim to achieve minimum execution times for different flight cancellation scenarios. By focusing exclusively on passenger recovery, we are able to adapt the optimization techniques to an entire airport closure, involving many affected airlines that may interact with one another. Furthermore, passenger relocation occurs within the context of a large-scale air transport network, in interaction with airlines, airports, and markets not initially affected by the closure.

Few papers on air transport resilience and vulnerability have modelled passenger recovery in this fashion. However, none of these studies use detailed demand data, and therefore, their rescheduling simulations do not take into account the original passenger itineraries. This is the methodological gap that we aim to cover. Cardillo et al. (2013), working with the European network, develop a passenger rescheduling algorithm and determine the change in network topology after simulating random failures. They define a multi-layered network, with each layer representing an individual airline's flight network. To make the rescheduling more realistic, passenger recovery options within the same layer are given priority. The results show that the definition of a multi-layered structure increases network damage as it restricts the options for passenger relocation. This methodological choice is relevant for our research purposes because it provides a clear way to implement different scenarios depending on the degree of interline cooperation. Also relevant is the paper by Hossain et al. (2013) on Australian airports, where variables such as airport capacity and ground transfers are included in the rescheduling algorithm. They find that the impact of a closure can be mitigated by having close surrogate airports to serve stranded passengers.

These conclusions also serve to highlight the challenging nature of air transport disruptions at tourism-oriented airports in comparison with other airports. First, tourism-oriented airports tend to experience strong seasonality (Dobruszkes, 2006), which challenges the ability of tourism businesses to plan and manage their labor and capital resources efficiently (Ruggieri, 2015). We submit that this argument also extends to the planning and management of resources needed to ensure resilient transport operations during peak periods. The reason is that seasonal traffic patterns affect airports' financial performance (Graham, 2013) and force managerial decisions into survival mode during off-peak periods (Eurocontrol, 2007). These 
difficulties persist even after medium-term activity forecasts became more reliable when traditional "holiday" charter airlines move to scheduled operations (De Wit and Zuidberg, 2016).

Table 1 identifies the most seasonal airports (highest ratio between August and February seat capacity in 2014) among the top-100 busiest airports in the European Economic Area. Inspecting this table, we can identify a second characteristic of tourism-oriented airports: they primarily handle origin-destination (OD) traffic (Dobruszkes, 2006). This means that passengers either initiate or terminate their journey at the airport. Therefore, they have a reduced set of transportation alternatives in the event of a closure in comparison with connecting passengers, for whom alternative intermediate hubs may be available. Third, there is a substantial number of tourist airports serving island destinations (for example, in the Mediterranean region). While larger islands can indeed be served by more than one airport, insularity adds to the aforementioned restrictions for passenger relocation by limiting the access to immediate road or rail transportation alternatives for international travel. Fourth, tourist airports are typically dominated by LCCs (Rey et al., 2011), which have different network structures than traditional, full-service carriers ${ }^{1}$ (Dobruszkes, 2013). On one hand, Lordan et al. (2016) does establish that the point-to-point flight network of LCCs is more robust, from a topological perspective, than the hub-and-spoke structures of traditional carriers. On the other hand, one must not forget that only a few LCCs belong to airline alliances, which effectively restricts their ability to relocate disrupted passengers in seats offered by partner airlines in the event of an airport closure. The conclusions of Cardillo et al. (2013) suggest that LCCs offer a worse quality of relocation by being restricted to their own flight networks when searching for relocation alternatives. We aim to investigate this in a context of evaluating "fairness" in service recovery across different airline types.

Table 1. Most seasonal airports among the top-100 busiest airports in the EEA (August 2014)

\begin{tabular}{|c|c|c|c|c|c|c|}
\hline $\begin{array}{l}\text { Airport } \\
\text { code }\end{array}$ & $\begin{array}{l}\text { Airport } \\
\text { name }\end{array}$ & Country & $\begin{array}{r}\text { Seasonality } \\
\text { factor }\end{array}$ & $\begin{array}{r}\text { low-cost/unallied } \\
\text { seat capacity \% }\end{array}$ & $\begin{array}{r}\text { OD passengers } \\
\%\end{array}$ & $\begin{array}{l}\text { Island } \\
\text { destination }\end{array}$ \\
\hline CFU & Corfu & Greece & 23.8 & $85.3 \%$ & $97.8 \%$ & Yes \\
\hline SPU & Split & Croatia & 13.1 & $52.0 \%$ & $98.6 \%$ & No \\
\hline IBZ & Ibiza & Spain & 10.7 & $82.3 \%$ & $97.4 \%$ & Yes \\
\hline $\mathrm{RHO}$ & Rhodes & Greece & 9.7 & $74.2 \%$ & $98.4 \%$ & Yes \\
\hline HER & Irakleion & Greece & 9.3 & $66.4 \%$ & $98.5 \%$ & Yes \\
\hline OLB & Olbia & Italy & 8.3 & $90.1 \%$ & $97.2 \%$ & Yes* \\
\hline MAH & Menorca & Spain & 7.8 & $87.2 \%$ & $98.6 \%$ & Yes \\
\hline PMI & Palma de Mallorca & Spain & 4.8 & $80.5 \%$ & $95.5 \%$ & Yes \\
\hline FAO & Faro & Portugal & 4.5 & $84.7 \%$ & $99.8 \%$ & No \\
\hline EMA & East Midlands & UK & 2.9 & $100.0 \%$ & $99.6 \%$ & No \\
\hline LBA & Leeds Bradford & UK & 2.7 & $91.5 \%$ & $99.8 \%$ & No \\
\hline KEF & Keflavik International & Iceland & 2.6 & $91.7 \%$ & $69.5 \%$ & Yes* \\
\hline LCA & Larnaca & Cyprus & 2.5 & $68.4 \%$ & $98.0 \%$ & Yes* \\
\hline AGP & Malaga & Spain & 2.4 & $75.9 \%$ & $99.4 \%$ & No \\
\hline ALC & Alicante & Spain & 2.2 & $86.0 \%$ & $99.2 \%$ & No \\
\hline $\mathrm{CAG}$ & Cagliari & Italy & 2.2 & $63.8 \%$ & $98.9 \%$ & Yes* \\
\hline SKG & Thessaloniki & Greece & 2.1 & $48.7 \%$ & $94.8 \%$ & No \\
\hline PSA & Pisa & Italy & 2.1 & $78.4 \%$ & $99.0 \%$ & No \\
\hline MLA & Malta & Malta & 2.0 & $86.3 \%$ & $96.3 \%$ & Yes \\
\hline ATH & Athens & Greece & 2.0 & $22.0 \%$ & $82.6 \%$ & No \\
\hline
\end{tabular}

In summary, this review of the transport literature supports the existence of a methodological gap related to the use of demand data to simulate multiple-airline recovery in the event of major disruptions. Existing papers, however, refer to the types of passenger impacts to be measured (delays and relocation rates) and give clues on how to implement airline

\footnotetext{
1 Some LCCs, such as Air Berlin or Vueling, have developed a "hybrid" strategy, allowing passenger connections at their main bases at Palma de Mallorca and Barcelona (Burghouwt, 2016). This type of traffic, however, is secondary to the main OD business of LCCs.
} 
cooperation in the model. In addition, the available evidence on air transport resilience supports the definition of tourism-oriented airports as a differentiated case study.

\section{DATA AND METHODOLOGY}

\subsection{A case study of Palma de Mallorca airport}

Palma de Mallorca Airport (IATA code: PMI) is the main airport serving the Balearic island of Mallorca (Spain), located in the Mediterranean. It is owned and operated by AENA (Spanish Airports and Airspace), which also operates most commercial airports in Spain. In August 2014, approximately $96 \%$ of passengers who passed through the airport either originated or terminated their journeys there. Therefore, PMI can be defined as mainly an origin-destination (OD) airport. For the purposes of this paper, however, we focus only on passenger departures. This airport (at its peak level of operation in August) is deemed a suitable case study as it meets the criteria stated in the introduction. First, as an island airport, disrupted departing passengers do not have access to alternative modes of transportation, such as rail or road, to reach their destinations. In addition, there is limited access to surrogate airports. The closest commercial airports are located on the islands of Ibiza and Menorca, both of which require a ferry transfer that exceeds 5 hours in duration. This makes departing passengers at PMI particularly vulnerable to airport closures in terms of potential travel delays. The airport is no stranger to these events. In July 2009, PMI remained closed for two hours after a terrorist attack in the island (to prevent the perpetrators from fleeing), which led to the disruption of 47 flights. AENA reinforced ATC services and coordinated with airlines and baggage handling companies to ensure a swift recovery (El País, 2009). In December 2010, airport operations at PMI were stopped for two days because of the nationwide ATC strike (El País, 2010). Many recovery measures were implemented: The government militarized ATC services to force controllers back into their posts. The airport operator advised departing passengers not to go to the airport until further notice to facilitate terminal operations. During the closure, ferry companies reinforced their services, as they became the only means of travel out of the island. Airlines had limited maneuverability and, only after flights resumed, Iberia deployed larger aircraft to PMI routes to increase its capacity for relocated passengers (Rtve, 2010). On a smaller scale, these disruptions have continued to occur due to frequent industrial actions across Europe. For example, 28 flights were cancelled at PMI because of the French ATC strike during Easter 2016 (Diario de Mallorca, 2016).

Second, PMI is a tourism-oriented airport with strong seasonal traffic. During the summer months, PMI becomes one of the busiest airports in Europe (Figure 1), due to the large number of visitors to the island. As a major inbound tourist market, most passenger departures at PMI are tourists returning their countries of residence after their holidays. This limits the ability of disrupted passengers to decide not to fly in the event of a cancellation and places great pressure on the airport and airlines to attend to the welfare of passengers until they are assigned an alternative itinerary. PMI's strong dependence on tourism translates into seasonal traffic flows. As observed in Figure 2, traffic during the peak month of August is between four and five times higher than it is during the off-peak months in the winter. This unevenness in monthly traffic is bound to challenge the ability of airlines and airports to plan and invest in measures to improve the resilience of air transport operations. 

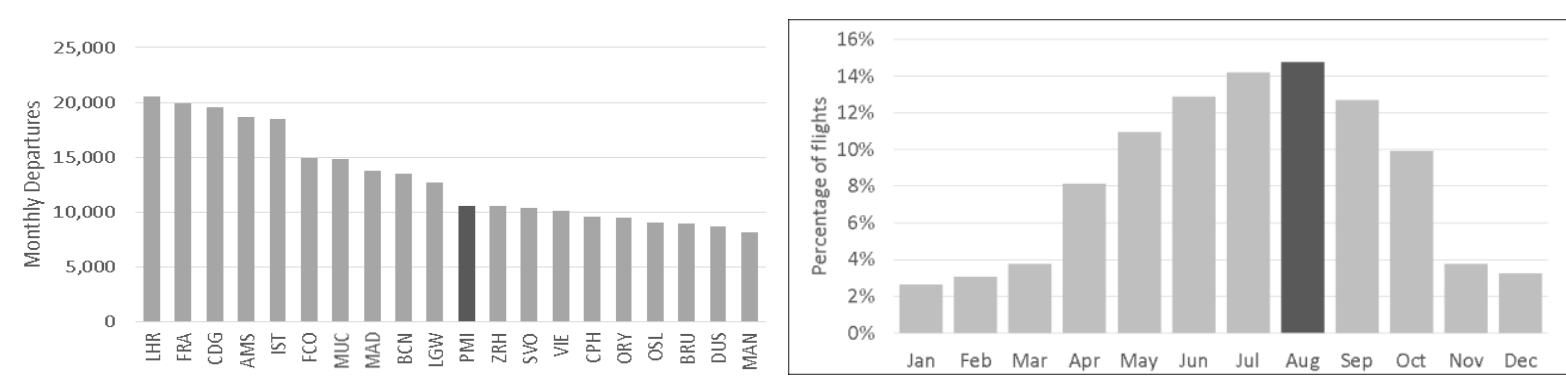

Figure 1 (left). Top-20 European airports by monthly departures (August 2014)

Figure 2 (right). Monthly distribution of flights at PMI airport (2014) Source: $O A G$

Third, while the airport is dominated by LCCs, we observe a diversity of business models, ranging from unallied no-frills carriers (Ryanair) to allied hybrid carriers (e.g., Air Berlin, a member of Oneworld). There is also a good representation of "holiday" airlines (e.g., Thomas Cook, Monarch) and even a small presence of traditional, full-service airlines (such as British Airways or Lufthansa). This allows a comparative analysis of the potential for passenger recovery between airline types. An additional depth of analysis is provided by focusing on the German and UK markets, which are the largest international markets served by the airport and account for $57 \%$ of departures during the sample month (Table 2). Table 3 provides disaggregated information on the top destinations and airlines in both markets according to the number of weekly departures. The largest carrier is Air Berlin, which operated more than 400 flights per week from PMI to German destinations in August 2014. In the UK market, the top carriers were Ryanair and EasyJet, which also serve the German market.

Table 2. Top-10 European markets departing from PMI (August 2014)

\begin{tabular}{lrr}
\hline Country & $\begin{array}{l}\text { \% OD passengers } \\
\text { over airport total }\end{array}$ & $\begin{array}{l}\text { \% indirect passengers } \\
\text { in country market }\end{array}$ \\
\hline 1. Germany & $37.0 \%$ & $1.0 \%$ \\
2. UK & $20.3 \%$ & $0.6 \%$ \\
3. Switzerland & $3.8 \%$ & $1.6 \%$ \\
4. France & $2.2 \%$ & $6.0 \%$ \\
5. Netherlands & $1.8 \%$ & $2.2 \%$ \\
6. Austria & $1.6 \%$ & $2.5 \%$ \\
7. Belgium & $1.5 \%$ & $0.7 \%$ \\
8. Italy & $1.5 \%$ & $12.9 \%$ \\
9. Denmark & $1.2 \%$ & $4.3 \%$ \\
10. Sweden & $1.0 \%$ & $20.1 \%$ \\
\hline \multicolumn{2}{c}{ Source: OAG }
\end{tabular}

Table 3. Top-10 airlines and destinations in Germany and UK markets served by PMI (August 2014)

\begin{tabular}{|c|c|c|c|c|c|c|c|}
\hline \multicolumn{4}{|c|}{ Germany market } & \multicolumn{4}{|c|}{ UK market } \\
\hline Airline & $\begin{array}{r}\text { Weekly } \\
\text { Departures }\end{array}$ & Destination & $\begin{array}{r}\text { Weekly } \\
\text { Departures }\end{array}$ & Airline & $\begin{array}{r}\text { Weekly } \\
\text { Departures }\end{array}$ & Destination & $\begin{array}{r}\text { Weekly } \\
\text { Departures }\end{array}$ \\
\hline Air Berlin & 407 & Dusseldorf & 96 & Easyjet & 126 & London Gatwick & 62 \\
\hline Germanwings & 109 & Koln/Bonn & 81 & Ryanair & 87 & Manchester & 58 \\
\hline Condor & 72 & Stuttgart & 67 & Jet2.com & 73 & East Midlands & 34 \\
\hline TUIfly & 57 & Frankfurt & 64 & Monarch & 62 & Birmingham & 32 \\
\hline Ryanair & 52 & Hamburg & 62 & Thomas Cook & 40 & Stansted & 29 \\
\hline Lufthansa & 25 & Munich & 62 & British Airways & 15 & London Luton & 28 \\
\hline Easyjet & 16 & Berlin Tegel & 50 & Flybe & 12 & Bristol & 24 \\
\hline Germania & 14 & Hannover & 40 & Thomson & 8 & Leeds-Bradford & 24 \\
\hline Vueling & 7 & Bremen & 27 & Condor & 5 & Newcastle & 23 \\
\hline Jetairfly & 1 & Nuremberg & 27 & Norwegian & 3 & Liverpool & 20 \\
\hline
\end{tabular}

Our empirical analysis is based on the traffic of an average Monday at PMI. The hourly distribution of flights is shown in Figure 3. This chart reveals three distinct waves of activity throughout the day: the morning wave, from 8:00 to 13:00 (peak traffic 10:00-12:00); the afternoon wave, from 13:00 to 19:00 (peak traffic 14:00-16:00); and the evening wave, from 
19:00 to $24: 00$ (peak traffic 22:00-24:00) ${ }^{2}$. This is used to define the closure scenarios. A scenario is defined by a combination of closure times and recovery constraints. All 19 scenarios included in this case study are shown in Table 4. In regards to the temporal scope, we include three short 2-hour closures that coincide with the peaks of activity shown in Figure 3; three medium-length closures for each of the daily traffic waves; and one full-day closure. In all instances, a recovery window of 48 hours is set, i.e., disrupted passengers can be relocated in alternative itineraries within a window of 48 hours after the closure ends. The implementation of a 48-hour recovery window (which is the computational limit to our depth of search for alternative itineraries) implies the assumption that passengers always accept a rerouting within the first 48 hours (instead of deciding not to travel). The choice of case study supports this simplification. The large cohort of inbound holiday passengers stranded at our insular airport will be less likely to reject a rerouting if offered one. The recent case of Sharm-el-Sheikh, with UK holidaymakers waiting for days, confirms that view. This fixed recovery window also preserves comparability across scenarios with different closure periods. In addition to looking at the total number of relocated passengers, the effectiveness of each scenario is measured by the average departure delays per passenger and other indicators linked to airline costs. Each scenario also sets the constraints that will guide the search for alternative itineraries. The most restrictive scenarios allow airlines to relocate only passengers with direct (non-stop) itineraries, within their own airline/alliance/partnership flight networks, and with seat capacity constraints. The least restrictive scenario allows both direct and indirect itineraries, across all airlines, and no seat capacity restrictions. The implementation of interline constraints to passenger recovery is based on the definition of a multi-layered air transport network, as suggested by Cardillo et al. (2013).

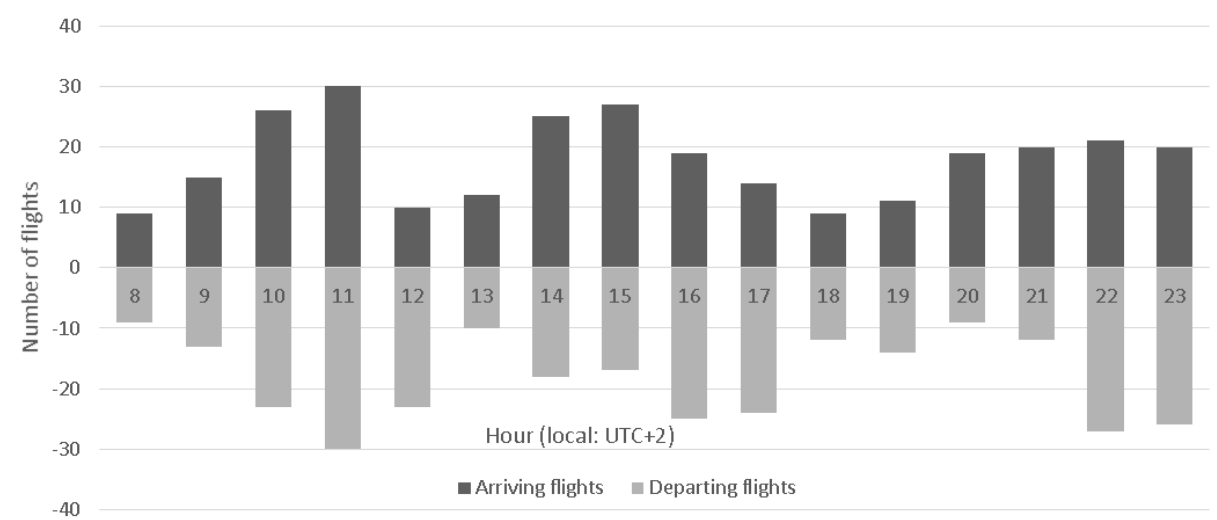

Figure 3. Hourly distribution of flights at PMI airport (average Monday August 2014) Source: $O A G$

Table 4. Recovery scenarios

\begin{tabular}{|c|c|c|c|c|c|}
\hline $\begin{array}{l}\text { beginning } \\
\text { closure - } \\
\text { Monday } \\
(\mathrm{UTC}+2)\end{array}$ & $\begin{array}{l}\text { end } \\
\text { closure - } \\
\text { Monday } \\
(\mathrm{UTC}+2)\end{array}$ & $\begin{array}{r}\text { 48h recovery window } \\
\text { direct flights only } \\
\text { own recovery } \\
\text { capacity restrictions }\end{array}$ & $\begin{array}{r}\text { 48h recovery window } \\
\text { direct and indirect } \\
\text { own recovery } \\
\text { capacity restrictions }\end{array}$ & $\begin{array}{r}\text { 48h recovery window } \\
\text { direct and indirect } \\
\text { interline recovery } \\
\text { capacity restrictions }\end{array}$ & $\begin{array}{l}\text { 48h recovery window } \\
\text { direct and indirect } \\
\text { interline recovery } \\
\text { no capacity restrictions }\end{array}$ \\
\hline $10: 00$ & $12: 00$ & scenario 1 & scenario 2 & & \\
\hline $15: 00$ & $17: 00$ & scenario 3 & scenario 4 & & \\
\hline $22: 00$ & $24: 00$ & scenario 5 & scenario 6 & & \\
\hline 08:00 & $13: 00$ & scenario 7 & scenario 8 & scenario 9 & \\
\hline $13: 00$ & $19: 00$ & scenario 10 & scenario 11 & scenario 12 & \\
\hline $19: 00$ & $24: 00$ & scenario 13 & scenario 14 & scenario 15 & \\
\hline 08:00 & $24: 00$ & scenario 16 & scenario 17 & scenario 18 & scenario 19 \\
\hline
\end{tabular}

The methodological process can be summarized as follows. First, a baseline travel dataset is generated by assigning flight numbers and travel times to passenger itineraries. Second, we

\footnotetext{
${ }^{2}$ All times are local $(\mathrm{UTC}+2)$.
} 
simulate each of the 19 closure scenarios, and the affected passengers are sequentially relocated in delay-minimizing itineraries that meet the scenario's constraints. Third, the impact of each closure is measured by several disruption indicators. Finally, a set of econometric regressions determines whether the quality of relocation differs across markets and airlines for selected scenarios.

\subsection{Datasets}

The proposed method combines worldwide supply (schedules and seats) and demand data (passenger itineraries). It is worth noting that the geographical scope of these datasets exceeds the destination map of PMI. This is done to reflect the seat capacity available in the European air transport system to accommodate the disrupted passengers at PMI. The supply side is covered by a dataset of worldwide flight schedules during the first week of August 2014, obtained from OAG Schedules. Each record indicates the operating airline, alliance membership (if applicable), flight number, origin and destination airport codes, number of seats, flight distance, departure time, and arrival times. The demand side is covered by an MIDT dataset for the first week of August 2014, which includes all passenger itineraries involving at least one European airport as origin, destination, or intermediate hub. Each record contains information on the ticketing airline and indicates the points of origin and destination, the connecting airports (up to two intermediate stops), and the number of passengers. The original sources of information for the MIDT dataset are Global Distributions Systems (GDSs) such as Galileo, Sabre, and Amadeus, among others. These raw data are processed by our data provider, OAG. Previous studies have used these datasets for the analysis of airport connectivity (Suau-Sánchez et al., 2014, 2015).

The proposed method requires three additional datasets: 1) a full list of alliance, codeshare, and interline partners for each published airline in the MIDT file. This information is obtained both from OAG and the airlines' websites; 2) airport-specific minimum connecting times, including approximately 68,000 airline-specific exceptions. This is obtained from the OAG Connections Analyser; and 3) minimum ground transfer times between the 50 largest airports in the European network and their potential surrogates. The surrogates are defined as airports located less than $130 \mathrm{~min}$ from a given airport in an uncongested road/rail transfer. This threshold represents the corresponding road/rail transfer time associated with the shortest flights in the schedule dataset. The travel times are easily obtained using Google Maps.

\subsection{Creating the baseline travel dataset}

Although the MIDT dataset provides information on passenger itineraries, it does not indicate the actual flights taken by the passengers or their travel times. Therefore, for each MIDT record, a search is performed in the OAG file for all relevant flights that were operated by either the published airline or any of its partners during the sample week. If the itinerary involves more than one sector, flight connections are built on the following restrictions, adapted from Grosche (2009) and Seredyński et al. (2014): a) The published minimum connecting times must be met, b) the maximum connecting time is arbitrarily set at one hour above the shortest valid connection time, c) passengers on each first-leg flight always prefer the shortest travel time, and d) passengers on each final-leg flight also prefer the shortest travel times.

Once the suitable flights (or flight combinations) are selected, the proportion of passengers allocated to each travel option is equal to the proportion of its seat capacity to the total capacity. After the first round of processing, the records in the baseline travel dataset are aggregated by flight number and departure date to check whether the number of passengers 
assigned to each individual flight exceeds the seat capacity of the aircraft. Passengers over capacity are removed from the baseline travel dataset and brought into new rounds of processing with updated seat capacities. For this paper, three sequential rounds are enough to ensure that $95 \%$ of all passengers in the MIDT file are allocated. The average load factor for intra-European flights that results from this processing is $78.6 \%$, which falls within the range of values reported for intra-European domestic and international markets by the Association of European Airlines (AEA, 2014) for August 2014 (78.3-81.5). The average travel times are 144 minutes for the German markets and 161 for the UK markets out of PMI. The baseline travel dataset and the predicted load factors for all European flights are brought forward into the next stage.

\subsection{Airport closures and passenger rescheduling}

An airport closure is characterized by a vector including the airport code and the times of the beginning and end of the closure. All flights scheduled to depart from the closed airport are labelled as "OFF". Of all remaining flights, those already at full capacity are labelled as "FULL", and the rest are "ON". Every disrupted demand record from the baseline travel dataset is compiled in a rescheduling matrix that indicates the number of passengers, the first flight in their itinerary to be rescheduled, and the final destination of their trip. This matrix is sorted by the original departure time to establish the sequence in which passengers will be relocated. Depending on the scenario, different passenger recovery options are considered: 1) relocation only in non-stop flights within the same airline, alliance, or partnership, 2) relocation via non-stop and indirect routes within the same airline, alliance, or partnership, and 3) unrestricted relocation (passengers can be relocated in suitable flights operated by all airlines). Only remaining "ON" flights can be used for passenger recovery, and all retain their original schedules. In addition, there is the possibility of transferring to other airports by ground transport with the objective to make flight connections or end the journey. This allows a disrupted passenger bound to a German destination to arrive at, for example, Frankfurt and take advantage of intermodal transport alternatives available at the airport terminal for medium- or long-distance rail travel. For simplicity, only road/rail travel times between airports in different cities are computed.

Table 5. Algorithm for passenger rescheduling

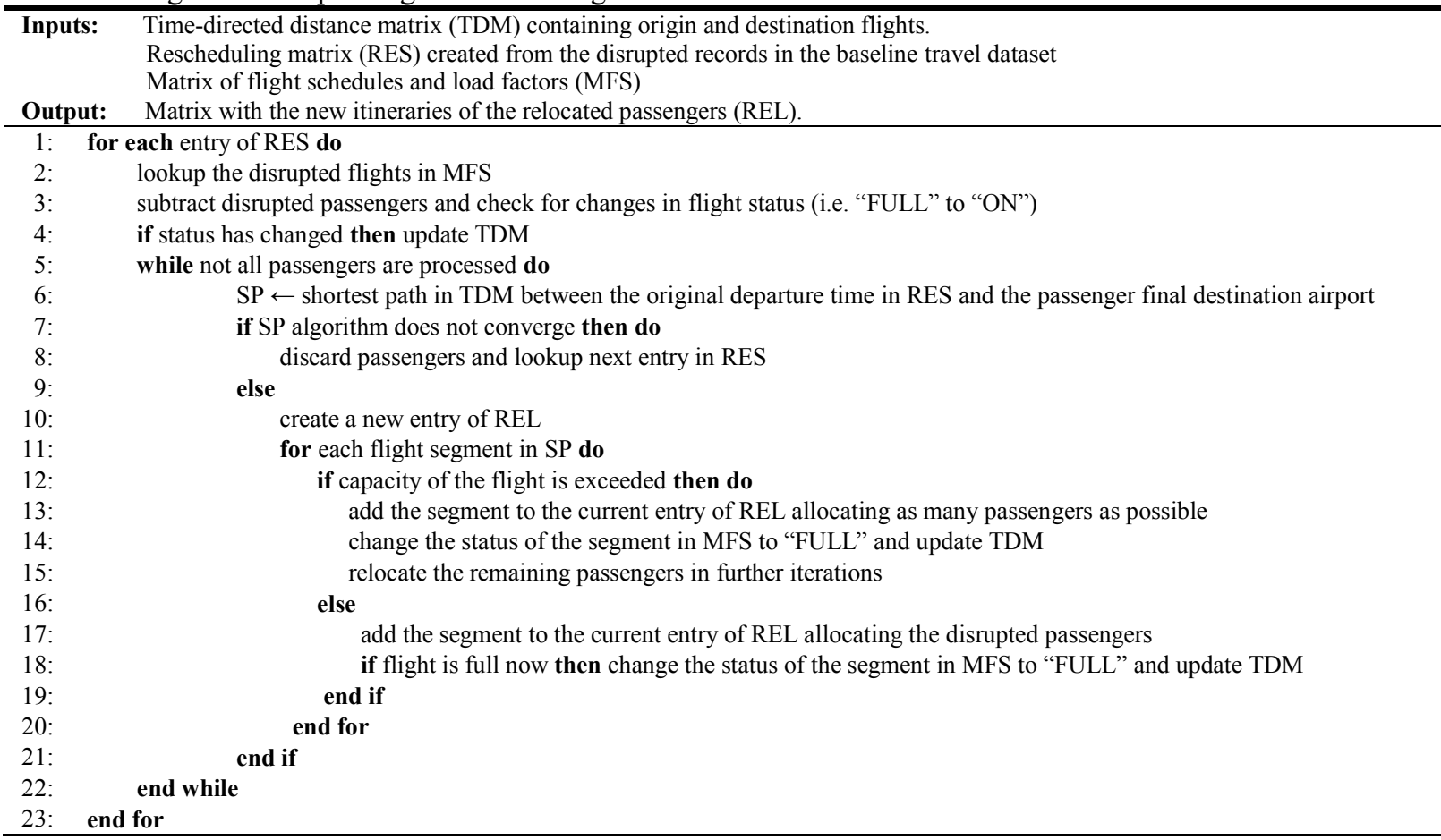


Once the scenario's constraints are implemented, the search for alternative routings for passenger recovery is driven by the objective of delay minimization, as is common in empirical applications (Barnhart, 2009). In real-world recovery scenarios, airlines face many competing objectives in their attempt to minimize the costs of disruption. Some of these objectives may be at odds with delay minimization (Rupp et al., 2005) ${ }^{3}$. In support of the simple approach that we employ is the fact that we do not introduce aircraft or crew relocation into our algorithm, which would bring the cost implications of recovery decisions to the forefront. However, there is still an implicit cost pressure to minimize delays to cut down on assistance costs, reimbursements, and passenger disgruntlement. Furthermore, our approach is supported by the regulatory statement that rerouting should be offered "at the earliest convenience".

A shortest-path-length algorithm is applied on a time-distance matrix comprising all remaining origin and destination flight nodes. The rescheduling algorithm finds the optimal alternative routing for the disrupted passengers in a dynamic and iterative process (Table 5). Capacity constraints are taken into account: If there is no spare capacity to allocate all disrupted passengers in their new itinerary, the excess passengers are taken aside and relocated in the next iteration using an updated distance matrix that reflects the changes in capacity. Any passenger who remains unallocated at the end of the process is flagged as such. The calculation of shortest-path itineraries is performed using the iGraph library in R (Csardi and Nepusz, 2006). This employs the well-known Dijkstra algorithm, which performs an exhaustive search that ensures that, if anything, a shortest path is always returned.

The impact of each closure is measured by the non-relocation rate (the proportion of passengers for whom an alternative itinerary was not found within the recovery window) and by the average departure delay experienced by the relocated passengers. Separate measures of impact are provided for the German and UK markets, and we also report the airports that serve the largest amounts of relocated traffic in each closure scenario. Additional measures are provided to discuss the potential costs for the airline in terms of passenger care. This is possible because of the regulations that establish delay thresholds that trigger several passenger rights. Therefore, we report the proportion of disrupted passengers for whom the airline has a duty of care (departure delays between 2-3 hours), the number of overnight stays by relocated passengers (proxy for accommodation expenses), and the proportion of passengers who would require ground transfers. We are unable to translate these measures into monetary costs due to a lack of data on the average meals, accommodation, and transport costs per passenger. However, with enough information, this calculation would be straightforward from our reported figures. Reimbursement costs are linked to non-relocated passengers, which we have already reported. In theory, delays above five hours also give passengers the right to reimbursement, but given the nature of our case study, inbound international holiday passengers are less likely to decide not to travel and seek reimbursement instead of the alternative itinerary. Given the focus of our paper on disruptive events that can certainly be classified as "extraordinary circumstances" (terror, weather, industrial actions), we do not include compensation costs either because airlines are exempt.

Finally, eight linear regressions are carried out to obtain additional insight on the factors affecting the quality of passenger recovery at PMI for UK and German markets in scenarios 17 and 18. The dependent variable is either the departure delay per passenger or the proportion of passengers relocated per airline and destination. The explanatory variables are original travel time (in days), traffic wave (morning, afternoon, or evening), geographical

\footnotetext{
${ }^{3}$ Recently, British Airways preferred to pay for two-night accommodations for approx. 100 stranded passengers in Cyprus after an aircraft had a technical fault rather than to quickly source a new aircraft (Daily Mail, 2016).
} 
market (UK or Germany), weekly frequencies to the destination (for either the relevant airline or the total for all airlines at PMI), airline type (low-cost or full-service), type of relocation (inline or interline), and a set of airline-specific dummy variables (with Germanwings as the reference airline). Two sets of specifications are run, one with interactions between airline type and geographical market and another with the individual airline dummies. (EasyJet and Ryanair are separated for German and UK markets because they have a large presence in both.) The total airline frequencies and interline variables are included in the models based on scenario 18, where interlining is allowed.

\section{RESULTS AND DISCUSSION}

\subsection{Simulation results}

Table 6 summarizes the main indicators of passenger disruption for each of the 19 scenarios. For short-length closures ( 2 hours), if airlines allow alternative itineraries involving at least one flight connection, rather than employing only non-stop recovery options, non-relocation rates are shown to decrease, on average, between 5\% and 30\% and reduce average passenger departure delays between 2 and 6 hours. Passengers disrupted by morning closures benefit the most from the increased recovery options due to the availability on onward travel options in the same day. In medium-length closures (5-6 hours), the lack of seat capacity makes interline cooperation necessary to achieve non-relocation rates below $10 \%$. This leads to further improvements in the speed to recovery between 7 and 8 hours per passenger. The same delay reductions, however, cannot be achieved by interline cooperation in the full-day closure scenario, which remains stable above 34 hours of average departure delay (scenarios 17 and 18). The non-relocation rate does indeed decrease by approximately $23 \%$, but it does not achieve the levels estimated for shorter closures, remaining at $15.6 \%$. The reason is again a lack of seat capacity. The fully unrestricted scenario (19) indicates that the lowest possible non-relocation rate is $2.9 \%$, and the lowest possible average departure delay is 13 hours and 55 minutes. This theoretical improvement is consistent with the conclusions of Wang (2007), who discusses how high load factors reduce the resilience of an air transport system by leaving little free capacity to relocate disrupted passengers. The disaggregated information on German and UK markets shows important differences in passenger disruption. In regards to improvements in the speed of recovery, German passengers consistently benefit more from indirect relocation, interlining, and additional capacity than UK passengers do. On the other hand, interline cooperation can always achieve 100\% relocation for UK markets in mediumlength closures, regardless of when they occur. Looking at the full-day closures, German markets recover more passengers under inline recovery, though these differences are greatly reduced after cooperation is allowed.

From a cost perspective, it is clear that airlines face a tradeoff between reimbursement and care/rerouting costs. As expected, a reduction in the non-relocation rate boosts the proportion of passengers for whom the airline has a duty of care, alongside the number of overnight stays and ground transfers required. Thus, airlines with higher fares (e.g., full-service airlines) have a greater incentive to implement measures to reduce the non-relocation rate than low-fare carriers. In regards to interlining, an additional cost-saving advantage is the significant reduction in average departure delays, which also bring a reduction in average overnight stays per relocated passenger. The opportunity to achieve faster and cheaper relocations by means of interlining is optimal in medium-length closures, which is when airlines still have enough capacity to share. In full-length closures, the massive backlog of disrupted passengers can also benefit from interlining, but capacity shortages make that process slower. 
Table 6. Summary of passenger disruption indicators per geographical market and closure scenario

\begin{tabular}{|c|c|c|c|c|c|c|c|c|c|c|c|c|c|c|}
\hline \multirow{2}{*}{\multicolumn{3}{|c|}{$\begin{array}{l}\text { scenario beginning end } \\
\text { closure closure }\end{array}$}} & \multicolumn{6}{|c|}{ Spain to EEA markets } & \multicolumn{3}{|c|}{ Spain to UK markets } & \multicolumn{3}{|c|}{ Spain to Germany markets } \\
\hline & & & \multirow{2}{*}{$\begin{array}{l}d p a x \\
4,060\end{array}$} & \multirow{2}{*}{$\begin{array}{c}\begin{array}{c}\text { \%non- } \\
\text { reloc }\end{array} \\
14.9 \%\end{array}$} & \multirow{2}{*}{$\begin{array}{c}\text { ocare } \\
82.0 \%\end{array}$} & \multirow{2}{*}{$\begin{array}{r}\text { nights } \\
2,953\end{array}$} & \multirow{2}{*}{$\begin{array}{l}\text { \%grt } \\
39.4 \%\end{array}$} & \multirow{2}{*}{$\begin{array}{l}\text { ddel/pax } \\
24 \text { h } 10 \text { m }\end{array}$} & \multirow{2}{*}{$\begin{array}{l}d p a x \\
2,694\end{array}$} & \multirow{2}{*}{$\begin{array}{c}\begin{array}{c}\text { \%non- } \\
\text { reloc }\end{array} \\
14.6 \%\end{array}$} & \multirow{2}{*}{$\begin{array}{l}\text { ddel/pax } \\
23 \text { h } 26 \text { m }\end{array}$} & \multirow{2}{*}{$\begin{array}{r}\text { dpax } \\
751\end{array}$} & \multirow{2}{*}{$\begin{array}{c}\begin{array}{c}\text { \%non- } \\
\text { reloc }\end{array} \\
4.4 \%\end{array}$} & \multirow{2}{*}{$\begin{array}{l}\text { ddel/pax } \\
26 \text { h } 06 \mathrm{~m}\end{array}$} \\
\hline 1 & $10: 00$ & $12: 00$ & & & & & & & & & & & & \\
\hline 2 & 10:00 & 12:00 & 4,060 & $4.3 \%$ & $89.4 \%$ & 2,309 & $49.6 \%$ & $18 \mathrm{~h} 46 \mathrm{~m}$ & 2,694 & $5.2 \%$ & $20 \mathrm{~h} 09 \mathrm{~m}$ & 751 & $0.0 \%$ & $18 \mathrm{~h} 15 \mathrm{~m}$ \\
\hline 3 & $15: 00$ & $17: 00$ & 3,022 & $29.6 \%$ & $67.0 \%$ & 1,400 & $47.6 \%$ & $16 \mathrm{~h} 41 \mathrm{~m}$ & 597 & $32.8 \%$ & $14 \mathrm{~h} 34 \mathrm{~m}$ & 1,477 & $18.3 \%$ & $14 \mathrm{~h} 36 \mathrm{~m}$ \\
\hline 4 & 15:00 & $17: 00$ & 3,022 & $5.5 \%$ & $90.7 \%$ & 1,422 & $51.9 \%$ & $14 \mathrm{~h} 03 \mathrm{~m}$ & 597 & $6.5 \%$ & $15 \mathrm{~h} 54 \mathrm{~m}$ & 1,477 & $2.0 \%$ & $13 \mathrm{~h} 03 \mathrm{~m}$ \\
\hline 5 & $22: 00$ & $24: 00$ & 2,310 & $36.6 \%$ & $63.0 \%$ & 1,904 & $43.1 \%$ & $21 \mathrm{~h} 50 \mathrm{~m}$ & 1,043 & $33.3 \%$ & $21 \mathrm{~h} 31 \mathrm{~m}$ & 565 & $39.5 \%$ & $11 \mathrm{~h} 30 \mathrm{~m}$ \\
\hline 6 & 22:00 & 24:00 & 2,310 & $7.7 \%$ & $92.2 \%$ & 2,636 & $43.2 \%$ & $19 \mathrm{~h} 46 \mathrm{~m}$ & 1,043 & $0.0 \%$ & $22 \mathrm{~h} 25 \mathrm{~m}$ & 565 & $18.1 \%$ & $10 \mathrm{~h} 51 \mathrm{~m}$ \\
\hline 7 & 08:00 & $13: 00$ & 11,181 & $26.0 \%$ & $73.7 \%$ & 6,807 & $37.8 \%$ & $24 \mathrm{~h} 13 \mathrm{~m}$ & 3,605 & $19.4 \%$ & $27 \mathrm{~h} 30 \mathrm{~m}$ & 5,793 & $25.7 \%$ & $21 \mathrm{~h} 20 \mathrm{~m}$ \\
\hline 8 & 08:00 & $13: 00$ & 11,181 & $16.0 \%$ & $82.2 \%$ & 6,087 & $40.6 \%$ & $20 \mathrm{~h} 41 \mathrm{~m}$ & 3,605 & $14.9 \%$ & $28 \mathrm{~h} 27 \mathrm{~m}$ & 5,793 & $17.0 \%$ & $16 \mathrm{~h} 31 \mathrm{~m}$ \\
\hline 9 & 08:00 & 13:00 & 11,181 & $2.2 \%$ & $96.5 \%$ & 3,850 & $60.9 \%$ & $13 \mathrm{~h} 36 \mathrm{~m}$ & 3,605 & $0.0 \%$ & $18 \mathrm{~h} 44 \mathrm{~m}$ & 5,793 & $4.2 \%$ & $10 \mathrm{~h} 20 \mathrm{~m}$ \\
\hline 10 & 13:00 & 19:00 & 9,164 & $25.6 \%$ & $74.0 \%$ & 6,990 & $37.5 \%$ & $24 \mathrm{~h} 55 \mathrm{~m}$ & 1,432 & $41.1 \%$ & $22 \mathrm{~h} 03 \mathrm{~m}$ & 5,040 & $19.7 \%$ & $26 \mathrm{~h} 08 \mathrm{~m}$ \\
\hline 11 & $13: 00$ & $19: 00$ & 9,164 & $16.0 \%$ & $83.3 \%$ & 6,214 & $40.1 \%$ & $20 \mathrm{~h} 07 \mathrm{~m}$ & 1,432 & $31.9 \%$ & $22 \mathrm{~h} 51 \mathrm{~m}$ & 5,040 & $10.2 \%$ & $20 \mathrm{~h} 14 \mathrm{~m}$ \\
\hline 12 & 13:00 & 19:00 & 9,164 & $2.7 \%$ & $93.2 \%$ & 4,883 & $69.6 \%$ & $12 \mathrm{~h} 47 \mathrm{~m}$ & 1,432 & $0.0 \%$ & $15 \mathrm{~h} 13 \mathrm{~m}$ & 5,040 & $0.6 \%$ & $12 \mathrm{~h} 11 \mathrm{~m}$ \\
\hline 13 & 19:00 & $24: 00$ & 8,523 & $22.2 \%$ & $77.2 \%$ & 8,144 & $36.1 \%$ & $26 \mathrm{~h} 47 \mathrm{~m}$ & 1,938 & $39.3 \%$ & $24 \mathrm{~h} 59 \mathrm{~m}$ & 4,083 & $36.7 \%$ & $23 \mathrm{~h} 33 \mathrm{~m}$ \\
\hline 14 & 19:00 & $24: 00$ & 8,523 & $12.0 \%$ & $87.2 \%$ & 8,700 & $39.4 \%$ & $21 \mathrm{~h} 37 \mathrm{~m}$ & 1,938 & $10.4 \%$ & $25 \mathrm{~h} 51 \mathrm{~m}$ & 4,083 & $14.4 \%$ & $18 \mathrm{~h} 14 \mathrm{~m}$ \\
\hline 15 & 19:00 & 24:00 & 8,523 & $6.1 \%$ & $92.4 \%$ & 7,691 & $59.5 \%$ & $13 \mathrm{~h} 55 \mathrm{~m}$ & 1,938 & $0.0 \%$ & $14 \mathrm{~h} 09 \mathrm{~m}$ & 4,083 & $12.7 \%$ & $13 \mathrm{~h} 35 \mathrm{~m}$ \\
\hline 16 & 08:00 & $24: 00$ & 28,736 & $43.9 \%$ & $56.0 \%$ & 23,456 & $28.7 \%$ & $36 \mathrm{~h} 06 \mathrm{~m}$ & 6,968 & $52.1 \%$ & $35 \mathrm{~h} 35 \mathrm{~m}$ & 14,824 & $38.6 \%$ & $37 \mathrm{~h} 07 \mathrm{~m}$ \\
\hline 17 & 08:00 & $24: 00$ & 28,736 & $38.5 \%$ & $60.6 \%$ & 24,437 & $29.1 \%$ & $34 \mathrm{~h} 36 \mathrm{~m}$ & 6,968 & $47.7 \%$ & $35 \mathrm{~h} 49 \mathrm{~m}$ & 14,824 & $33.6 \%$ & $34 \mathrm{~h} 58 \mathrm{~m}$ \\
\hline 18 & 08:00 & $24: 00$ & 28,736 & $15.6 \%$ & $81.6 \%$ & 33,739 & $53.1 \%$ & $34 \mathrm{~h} 21 \mathrm{~m}$ & 6,968 & $13.3 \%$ & $34 \mathrm{~h} 36 \mathrm{~m}$ & 14,824 & $14.1 \%$ & $33 \mathrm{~h} 44 \mathrm{~m}$ \\
\hline 19 & 08:00 & 24:00 & 28,736 & $2.9 \%$ & $94.0 \%$ & 6,968 & $67.2 \%$ & $13 \mathrm{~h} 18 \mathrm{~m}$ & 6,968 & $0.0 \%$ & $14 \mathrm{~h} 02 \mathrm{~m}$ & 14,824 & $5.0 \%$ & $13 \mathrm{~h} 22 \mathrm{~m}$ \\
\hline
\end{tabular}

Table 7 shows the results of the linear regressions on scenarios 17 and 18 (full-day closures with and without interline restrictions). When interlining is not allowed, airline frequencies do not have a significant impact on either departure delays or relocation rates. While more frequencies create more capacity for inline relocation, they also increase the potential number of disrupted passengers in the event of a closure, hence the ambiguous impact. When interlining is allowed, the estimated coefficients clearly indicate that the most popular destinations (the ones with the highest weekly frequencies; see Table 3) enjoy higher relocation rates but also longer departure delays. At an airline level, airlines with more frequencies - and thus a larger number of disrupted passengers - experience lower relocation rates. Another result that is consistent across specifications is that passengers on disrupted afternoon and evening flights have worse prospects of recovery than those on disrupted morning flights, which take precedence in our relocation algorithm. For routes above the average travel time (approx. 0.1 days), interlining has a negative impact only on departure delays per passenger.

Table 7. Linear regressions for selected scenarios

\begin{tabular}{|c|c|c|c|c|c|c|c|c|c|c|c|c|c|c|c|c|}
\hline \multirow[t]{3}{*}{ Dependent variable } & \multicolumn{8}{|c|}{ Departure delay per passenger } & \multicolumn{8}{|c|}{$\%$ relocated passengers per airline and destination } \\
\hline & \multicolumn{4}{|c|}{ Scenario 17} & \multicolumn{4}{|c|}{ Scenario 18} & \multicolumn{4}{|c|}{$\begin{array}{c}\text { Scenario } 17 \\
\end{array}$} & \multicolumn{4}{|c|}{ Scenario 18} \\
\hline & Coeff. & s.d. & Coeff. & s.d. & Coeff. & s.d. & Coeff. & s.d. & Coeff. & s.d. & Coeff. & s.d. & Coeff. & s.d. & Coeff. & s.d. \\
\hline Constant & 0.920 & 0.185 & 1.091 & 0.214 & 0.883 & 0.143 & 0.942 & 0.145 & 3.922 & 1.499 & 0.528 & 0.372 & 2.274 & 1.393 & 1.268 & 0.887 \\
\hline Original travel time & 4.646 & 1.805 & 2.473 & 2.022 & 2.147 & 1.375 & 1.750 & 1.375 & 2.275 & 3.139 & 4.132 & 3.521 & -5.884 & 8.418 & -4.304 & 8.373 \\
\hline Weekly frequency (airline) & -0.002 & 0.008 & 0.007 & 0.007 & -0.004 & 0.003 & -0.003 & 0.004 & 0.003 & 0.012 & -0.010 & 0.013 & -0.038 & 0.012 & -0.033 & 0.012 \\
\hline Weekly frequency (total) & & & & & 0.004 & 0.001 & 0.004 & 0.001 & & & & & 0.016 & 0.004 & 0.014 & 0.005 \\
\hline Afternoon flight & 0.289 & 0.043 & 0.365 & 0.045 & 0.572 & 0.013 & 0.565 & 0.014 & -0.270 & 0.068 & -0.293 & 0.074 & -0.138 & 0.055 & -0.129 & 0.060 \\
\hline Evening flight & 0.542 & 0.060 & 0.616 & 0.057 & 0.812 & 0.016 & 0.811 & 0.017 & -0.649 & 0.071 & -0.672 & 0.072 & -0.296 & 0.114 & -0.362 & 0.116 \\
\hline Interline & & & & & 0.333 & 0.151 & 0.375 & 0.150 & & & & & -1.150 & 1.003 & -1.110 & 1.007 \\
\hline Interline travel time & & & & & -3.568 & 1.451 & -4.052 & 1.442 & & & & & 11.328 & 9.523 & 10.598 & 9.625 \\
\hline Full service_UK & -0.551 & 0.092 & & & -0.014 & 0.033 & & & -0.143 & 0.246 & & & -0.037 & 0.162 & & \\
\hline Low Cost_ŪK & 0.112 & 0.053 & & & 0.124 & 0.016 & & & -0.068 & 0.087 & & & -0.029 & 0.058 & & \\
\hline Full Service_DE & -0.076 & 0.050 & & & -0.007 & 0.018 & & & 0.113 & 0.085 & & & 0.002 & 0.061 & & \\
\hline Air Berlin & & & -0.160 & 0.064 & & & -0.028 & 0.025 & & & 0.177 & 0.117 & & & 0.029 & 0.086 \\
\hline British Airways & & & -0.542 & 0.146 & & & -0.025 & 0.059 & & & 0.463 & 0.313 & & & 0.117 & 0.208 \\
\hline Flybe & & & -0.012 & 0.223 & & & 0.076 & 0.066 & & & -0.050 & 0.355 & & & 0.422 & 0.235 \\
\hline Condor & & & 0.048 & 0.080 & & & -0.017 & 0.029 & & & -0.095 & 0.153 & & & 0.136 & 0.096 \\
\hline Norwegian & & & -0.335 & 1.794 & & & 0.130 & 0.718 & & & & & & & & \\
\hline Iberia & & & -0.706 & 0.591 & & & -0.276 & 0.235 & & & & & & & & \\
\hline Lufthansa & & & 0.521 & 0.378 & & & -0.150 & 0.052 & & & -0.511 & 0.286 & & & -0.019 & 0.187 \\
\hline Jet2.com & & & -0.022 & 0.095 & & & 0.120 & 0.030 & & & -0.253 & 0.162 & & & 0.042 & 0.105 \\
\hline SAS & & & -0.411 & 1.796 & & & 0.163 & 0.718 & & & & & & & & \\
\hline
\end{tabular}




\begin{tabular}{|c|c|c|c|c|c|c|c|c|}
\hline Germania & & 0.363 & 0.133 & 0.065 & 0.043 & -0.241 & 0.211 & 0.0060 .140 \\
\hline Thomas Cook & & -0.538 & 0.112 & -0.017 & 0.042 & -0.030 & 0.228 & $\begin{array}{lll}0.058 & 0.147\end{array}$ \\
\hline Air Europa & & -0.917 & 0.903 & 0.089 & 0.361 & & & \\
\hline Vueling & & -1.059 & 0.208 & 0.170 & 0.082 & 0.403 & 0.459 & $0.005 \quad 0.297$ \\
\hline TUIfly & & 0.254 & 0.087 & -0.074 & 0.029 & -0.169 & 0.153 & 0.0400 .098 \\
\hline Monarch Airlines & & -0.184 & 0.095 & 0.126 & 0.035 & 0.137 & 0.188 & 0.0910 .119 \\
\hline Ryanair_UK & & 0.322 & 0.093 & 0.173 & 0.028 & -0.325 & 0.143 & -0.0290 .096 \\
\hline Ryanair_DE & & -0.576 & 0.114 & -0.178 & 0.033 & 0.202 & 0.168 & $0.115 \quad 0.111$ \\
\hline Easyjet_UK & & 0.408 & 0.086 & 0.058 & 0.028 & -0.249 & 0.137 & -0.1300 .093 \\
\hline Easyjet_DE & & -0.532 & 0.128 & -0.010 & 0.046 & 0.057 & 0.207 & $-0.082 \quad 0.138$ \\
\hline Number of observations & 585 & 585 & 873 & 873 & 158 & 158 & 158 & 158 \\
\hline R-squared & 0.206 & 0.351 & 0.815 & 0.825 & 0.415 & 0.472 & 0.398 & 0.520 \\
\hline
\end{tabular}

Table 7 also indicates that LCCs (particularly EasyJet and Ryanair) have longer departure delays in UK markets than in German markets. These significant differences persist even in the interline equations, which tend to show smaller individual effects because airlines are effectively sharing their seat capacity. Ryanair also has a significantly lower proportion of inline relocated passengers in UK markets. (EasyJet's negative effect is significant at a $10 \%$ level.) On the other hand, full-service carriers in the UK (which handle a minority of traffic) have lower departure delays than German ones.

Further details on the performance of individual airlines when restricted to their own airline/partnership/alliance networks is provided in Figures 4 and 5 (for German and UK markets, respectively) and in Table 8. Note how EasyJet and Ryanair recover less than the market average of its disrupted UK and German passengers due to the lack of seat capacity in their networks. On the other hand, the recovery rates of low-cost/hybrid carriers Air Berlin (member of Oneworld), Germanwings (owned by Lufthansa), and Vueling (partnered with Iberia and British Airways) are higher than the respective market averages. Furthermore, in the regression analysis, these figures suggest that airline partnerships boost the resilience of LCCs' flight networks since they provide additional onward connectivity for rerouting passengers. In addition, note how airlines in German markets show a more consistent quality and speed of recovery than their UK counterparts, and the busiest German airlines have better relocation rates than the busiest UK ones. This evidence also suggests an asymmetry in the quality of relocation between the main geographical markets in PMI in the absence of interline cooperation.

Table 8. Airline relocation rates in scenario 17

\begin{tabular}{|c|c|c|c|c|c|c|c|}
\hline \multicolumn{4}{|c|}{ UK market } & \multicolumn{4}{|c|}{ Germany market } \\
\hline Airline & Code & dpax & \%reloc & Airline & Code & dpax & \%reloc \\
\hline Easyjet & U2 & 2,188 & $38.8 \%$ & Air Berlin & $\mathrm{AB}$ & 7,737 & $68.6 \%$ \\
\hline Ryanair & FR & 1,739 & $39.4 \%$ & Germanwings & $4 \mathrm{U}$ & 1,641 & $67.9 \%$ \\
\hline Jet2.com & LS & 1,506 & $53.3 \%$ & Condor & DE & 1,447 & $81.8 \%$ \\
\hline Monarch & $\mathrm{ZB}$ & 673 & $89.3 \%$ & TUIfly & $\mathrm{X} 3$ & 1,265 & $61.3 \%$ \\
\hline Thomas Cook & TCX & 416 & $88.9 \%$ & Ryanair & FR & 1,001 & $46.7 \%$ \\
\hline British Airways & BA & 176 & $100.0 \%$ & Germania & ST & 484 & $52.7 \%$ \\
\hline Flybe & $\mathrm{BE}$ & 139 & $51.1 \%$ & Easyjet & $\mathrm{U} 2$ & 457 & $57.8 \%$ \\
\hline Air Europa & UX & 4 & $100.0 \%$ & Lufthansa & LH & 219 & $10.5 \%$ \\
\hline Vueling & VY & 2 & $100.0 \%$ & Vueling & VY & 81 & $100.0 \%$ \\
\hline
\end{tabular}

Note: dpax $=$ disrupted passengers $; \%$ reloc $=\%$ passengers relocated within the recovery window. 


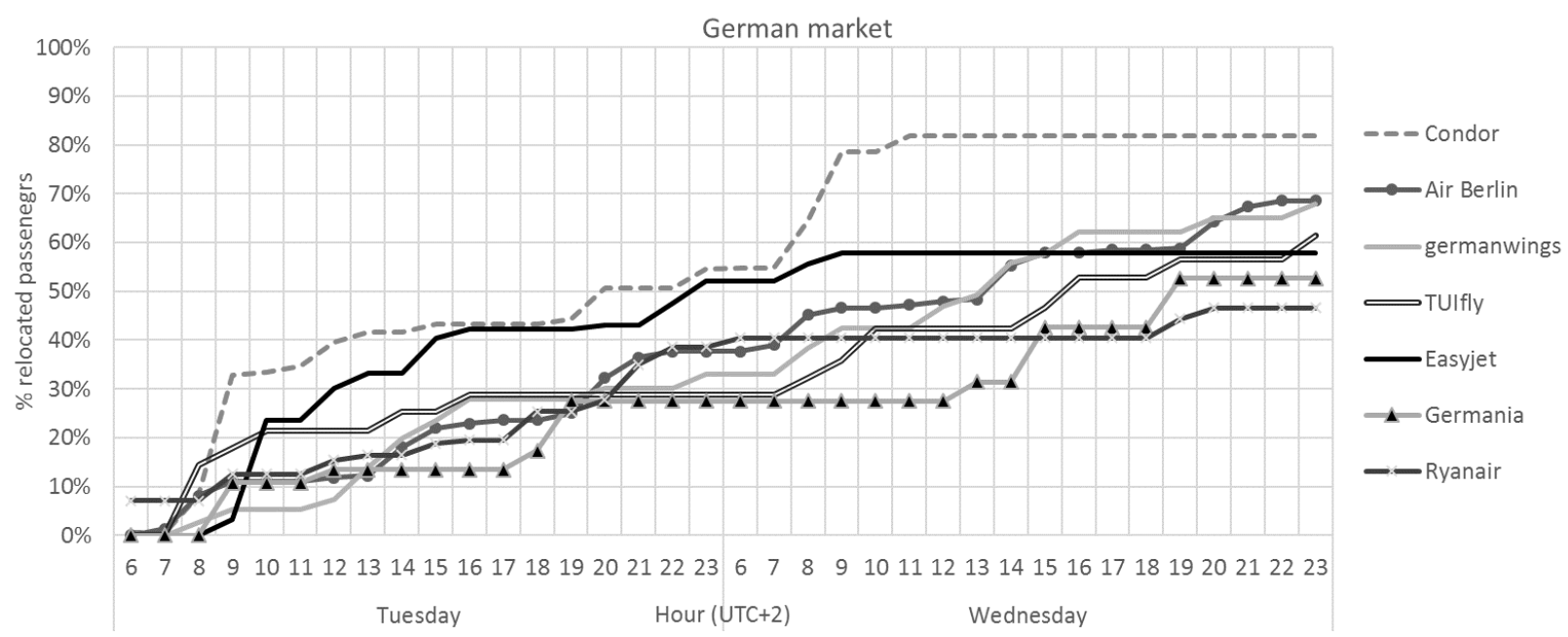

Figure 4. Hourly distribution of passenger relocation for individual airlines: German market (Scenario 17) Source: Own elaboration

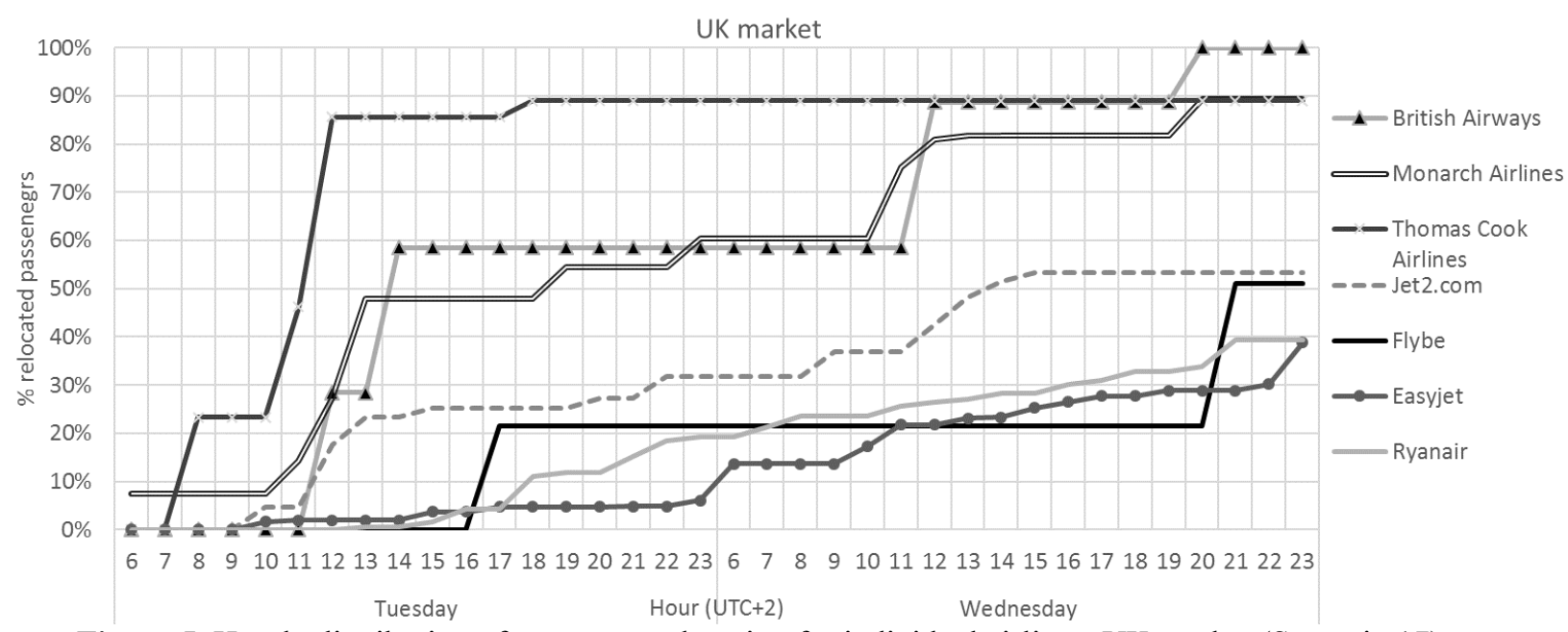

Figure 5. Hourly distribution of passenger relocation for individual airlines: UK market (Scenario 17) Source: Own elaboration

Table 9 provides information on the proportion of disrupted passengers from the largest airlines than could potentially take advantage of a cooperative agreement to share seat capacity (full relocation matrix in Appendix A). The main conclusion from this matrix is that there are no substantial imbalances between seats given to and seats taken from the pool. The heterogeneous distribution of flight schedules across the week allows all airlines to both contribute to and benefit from a hypothetical agreement. For example, Air Berlin, which has by far the largest number of frequencies at PMI for the markets under study, only provides minimum-delay itineraries for $38.3 \%$ of its relocated passengers, while $11.3 \%$ of passengers could be served better by Condor's spare capacity. Conversely, Air Berlin could accommodate $25.8 \%$ of Condor passengers. This perspective of mutual benefit from the collaborative scheme is bound to facilitate negotiations between the airlines. 
Table 9. Interline relocation matrix between largest airlines in scenario 18

\begin{tabular}{|c|c|c|c|c|c|c|c|c|c|c|c|c|c|c|}
\hline $\begin{array}{l}(\% \\
\text { relocated } \\
\text { passengers) }\end{array}$ & $\begin{array}{r}\text { Relocated } \\
\text { airline }\end{array}$ & 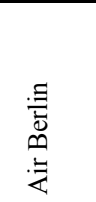 & 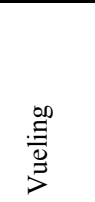 & 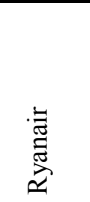 & 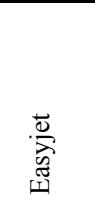 & 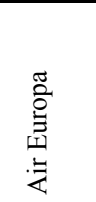 & 节 & $\begin{array}{l}\breve{~} \\
\dot{0} \\
0 \\
\tilde{n} \\
\tilde{\Xi} \\
\bar{E}\end{array}$ & 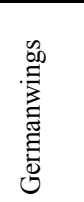 & 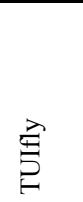 & $\bar{z}$ & 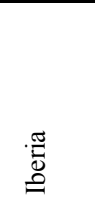 & 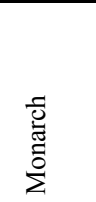 & 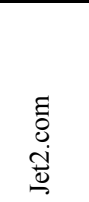 \\
\hline Disrupted airline & ne code & $\mathrm{AB}$ & VY & FR & $\mathrm{U} 2$ & UX & $\mathrm{DE}$ & TCX & $4 \mathrm{U}$ & $\mathrm{X} 3$ & $\mathrm{HG}$ & IB & $\mathrm{ZB}$ & LS \\
\hline Air Berlin & $\mathrm{AB}$ & $38.3 \%$ & $9.4 \%$ & $5.2 \%$ & $1.9 \%$ & $2.7 \%$ & $11.3 \%$ & $0.0 \%$ & $7.1 \%$ & $5.6 \%$ & $1.8 \%$ & $2.3 \%$ & $0.7 \%$ & $0.0 \%$ \\
\hline Ryanair & FR & $21.4 \%$ & $6.8 \%$ & $7.1 \%$ & $8.7 \%$ & $4.9 \%$ & $1.1 \%$ & $8.2 \%$ & $3.2 \%$ & $1.0 \%$ & $3.3 \%$ & $3.7 \%$ & $5.9 \%$ & $5.2 \%$ \\
\hline Easyjet & $\mathrm{U} 2$ & $8.8 \%$ & $7.1 \%$ & $12.3 \%$ & $16.7 \%$ & $8.3 \%$ & $0.1 \%$ & $15.1 \%$ & $3.2 \%$ & $0.4 \%$ & $1.9 \%$ & $2.3 \%$ & $5.5 \%$ & $7.4 \%$ \\
\hline Germanwings & $4 \mathrm{U}$ & $53.3 \%$ & $5.2 \%$ & $2.8 \%$ & $0.5 \%$ & $4.4 \%$ & $5.3 \%$ & $0.0 \%$ & $8.5 \%$ & $9.0 \%$ & $5.9 \%$ & $0.0 \%$ & $0.0 \%$ & $0.0 \%$ \\
\hline Jet2.com & LS & $11.8 \%$ & $13.9 \%$ & $18.3 \%$ & $8.6 \%$ & $15.5 \%$ & $0.0 \%$ & $0.3 \%$ & $0.0 \%$ & $0.0 \%$ & $0.0 \%$ & $12.4 \%$ & $3.3 \%$ & $7.7 \%$ \\
\hline Condor & $\mathrm{DE}$ & $25.8 \%$ & $5.5 \%$ & $3.0 \%$ & $9.1 \%$ & $6.2 \%$ & $1.4 \%$ & $8.5 \%$ & $9.4 \%$ & $6.1 \%$ & $0.5 \%$ & $0.0 \%$ & $4.5 \%$ & $1.5 \%$ \\
\hline TUIfly & $\mathrm{X} 3$ & $20.1 \%$ & $11.7 \%$ & $3.7 \%$ & $6.0 \%$ & $2.2 \%$ & $17.1 \%$ & $8.4 \%$ & $2.9 \%$ & $9.4 \%$ & $4.9 \%$ & $0.4 \%$ & $0.9 \%$ & $0.0 \%$ \\
\hline Monarch & $\mathrm{ZB}$ & $3.1 \%$ & $9.8 \%$ & $9.2 \%$ & $3.4 \%$ & $16.2 \%$ & $0.0 \%$ & $3.9 \%$ & $1.6 \%$ & $0.0 \%$ & $0.0 \%$ & $4.5 \%$ & $13.5 \%$ & $10.3 \%$ \\
\hline Vueling & VY & $9.3 \%$ & $40.7 \%$ & $2.1 \%$ & $4.9 \%$ & $3.2 \%$ & $0.0 \%$ & $0.0 \%$ & $6.1 \%$ & $3.5 \%$ & $1.2 \%$ & $7.9 \%$ & $11.1 \%$ & $0.0 \%$ \\
\hline NIKI & HG & $4.6 \%$ & $2.6 \%$ & $0.0 \%$ & $2.5 \%$ & $0.0 \%$ & $22.0 \%$ & $0.0 \%$ & $0.0 \%$ & $0.0 \%$ & $63.4 \%$ & $4.9 \%$ & $0.0 \%$ & $0.0 \%$ \\
\hline Thomas Cook & TCX & $19.5 \%$ & $4.3 \%$ & $10.1 \%$ & $20.4 \%$ & $7.7 \%$ & $0.0 \%$ & $22.1 \%$ & $0.0 \%$ & $0.0 \%$ & $0.0 \%$ & $0.0 \%$ & $2.2 \%$ & $12.7 \%$ \\
\hline
\end{tabular}

In regards to the implementation of airline recovery strategies, regardless of the extent of collaboration, it must be clarified that the scope of the disruption extends well beyond the airport originally affected. To illustrate this, Table 10 shows the top-ten airports that experience the highest increase in passenger departures as a result of the modelled recovery process for both UK and German markets in Scenarios 17 and 18. In Scenario 17 (without collaboration), the busiest alternate airports correlate with the top destinations served by the airlines at PMI. Beyond flight frequency, the alternate airport's geographic location plays an important role in allowing convenient onward travel by rail or road (less than $130 \mathrm{~min}$ to the passenger's final destination). This explains, for example, how Manchester Airport (within short reach of other popular destinations, such as Birmingham, East Midlands, Leeds, and Liverpool) is present in the highest proportion of delay-minimizing itineraries for UK stranded passengers. In the scenario with collaboration (18), two interesting results are observed: 1) the role of primary European hubs, such as Heathrow and Frankfurt, as potential gateways for passenger recovery and 2) the increased concentration in disrupted passenger shares handled by alternate airports. This is evident from Table 10, as the aggregate share of top-ten alternates increases from $27.3 \%$ to $76.2 \%$ in the UK markets because of cooperation. This presents many advantages in terms of resource planning in the event of a closure because any planned investments towards improving resilience can be focused in fewer places, with fewer stakeholders involved.

Table 10. Top-ten busiest alternative airports for selected geographical markets and scenarios

\begin{tabular}{|c|c|c|c|c|c|c|c|c|c|c|c|}
\hline \multicolumn{3}{|l|}{ UK scenario 17} & \multicolumn{3}{|c|}{ UK scenario 18} & \multicolumn{3}{|c|}{ Germany scenario 17} & \multicolumn{3}{|c|}{ Germany scenario 18} \\
\hline Alternate & $\Delta p a x$ & $\% d p a x$ & Alternate & $\Delta p a x$ & $\% d p a x$ & Alternate & $\Delta p a x$ & \%dpax & Alternate & $\Delta p a x$ & $\% d p a x$ \\
\hline Manchester & 523 & $7.5 \%$ & Heathrow & 1,214 & $17.4 \%$ & Dusseldorf & 1,758 & $11.9 \%$ & Frankfurt & 2,072 & $14.0 \%$ \\
\hline Stansted & 239 & $3.4 \%$ & Manchester & 909 & $13.0 \%$ & Berlin Tegel & 972 & $6.6 \%$ & Dusseldorf & 1,605 & $10.8 \%$ \\
\hline East Midlands & 227 & $3.3 \%$ & Dublin & 560 & $8.0 \%$ & Frankfurt & 861 & $5.8 \%$ & Berlin Tegel & 1,034 & $7.0 \%$ \\
\hline Gatwick & 158 & $2.3 \%$ & Stansted & 496 & $7.1 \%$ & Koln/Bonn & 841 & $5.7 \%$ & Hamburg & 1,012 & $6.8 \%$ \\
\hline Edinburgh & 155 & $2.2 \%$ & Birmingham & 413 & $5.9 \%$ & Munich & 811 & $5.5 \%$ & Munich & 715 & $4.8 \%$ \\
\hline Dublin & 153 & $2.2 \%$ & Gatwick & 378 & $5.4 \%$ & Stuttgart & 746 & $5.0 \%$ & Stuttgart & 687 & $4.6 \%$ \\
\hline Brussels & 146 & $2.1 \%$ & Ibiza & 372 & $5.3 \%$ & Hamburg & 708 & $4.8 \%$ & Brussels & 664 & $4.5 \%$ \\
\hline Luton & 109 & $1.6 \%$ & Amsterdam & 341 & $4.9 \%$ & Nuremberg & 436 & $2.9 \%$ & Zurich & 623 & $4.2 \%$ \\
\hline Liverpool & 97 & $1.4 \%$ & Barcelona & 324 & $4.6 \%$ & Brussels & 386 & $2.6 \%$ & Barcelona & 546 & $3.7 \%$ \\
\hline Ibiza & 94 & $1.3 \%$ & Edinburgh & 304 & $4.4 \%$ & Madrid & 348 & $2.3 \%$ & Koln/Bonn & 480 & $3.2 \%$ \\
\hline
\end{tabular}

Note: Apax = increase in departures with respect to baseline travel dataset; \%dpax $=\%$ of disrupted passengers relocated via the airport. 


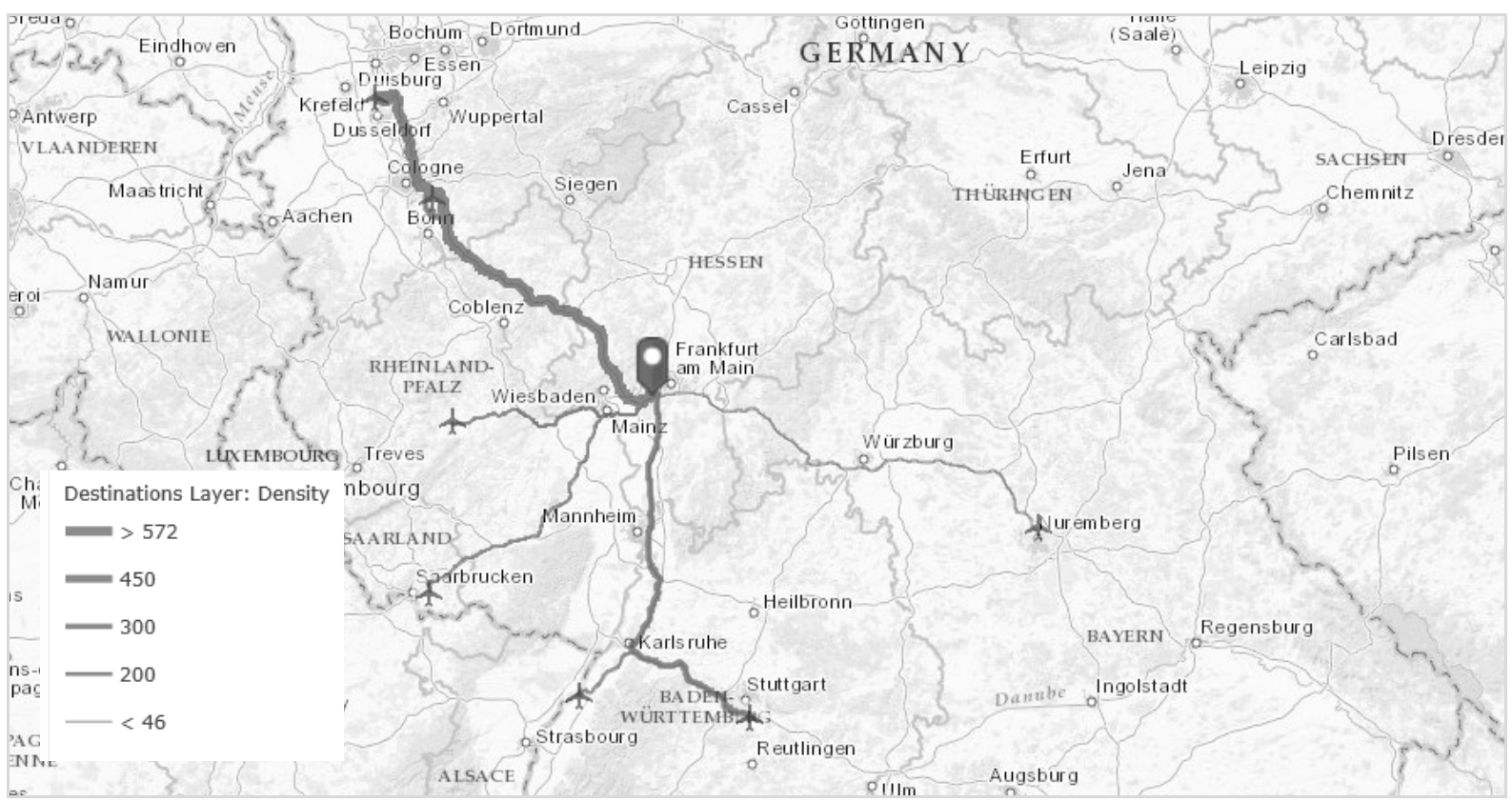

Figure 6. Ground transfers from Frankfurt to onward German destinations (Scenario 18)

Source: Own elaboration

Amongst other factors, the role of large European hubs in improving the quality of airline recovery is built upon good intermodal connectivity with neighbouring regions. This is shown by investigating how Frankfurt airport processes the 2,072 relocated passengers it receives in Scenario 18. Our simulation output indicates that 1,550 of these passengers continue their travel by rail or road (Figure 6). This expands the scope of the policy discussion on air transport resilience at tourist destinations and effectively links it to the highlevel objectives of improving intermodality and airport accessibility currently defined by the European Commission (EC, 2014).

\subsection{Implications}

These results have many policy and managerial implications. From the point of view of the airlines serving the tourist destination, the improvement in the quality of relocation can be expected to reduce the likelihood of negative word-of-mouth being generated and increase the loyalty of the disrupted passengers. Resilience planning should be an integral part of managerial decision-making, as a single disruption at a major destination can have damaging impacts on passenger numbers in the future and require substantial marketing efforts to restore the trust of consumers. In that regard, shortening passengers' waiting time at the airport and achieving a more consistent quality of recovery across geographical markets can improve the perception of "fairness" associated to the recovery process (Akamavi et al., 2016). Any additional effort towards collaboration between airlines at the disrupted airport, as well as with further agents in onward destinations, will be evident to the disrupted passengers and, via the moderation effect of "controllability" (Nibkin et al., 2015), also help make the recovery process more satisfying. These results also contribute to the literature in regards to the positive impact of multi-party collaboration within a context of tourism crisis management (Xu and Grunewald, 2009). In this regard, we conclude that interline cooperation works optimally in medium-length closures (5-6 hours), which is when airlines still have sufficient capacity to recover quickly. In full-day closures, cooperation is also beneficial, but capacity restrictions make the process of sharing capacity slower. Furthermore, it is important that the negotiations to establish an airline cooperation scheme be grounded upon the realization that airlines can both benefit from and contribute seats to 
delay-minimizing recovery itineraries, despite the differences in the individual airline recovery profiles.

The airport will experience increased non-aeronautical revenues due to longer passenger dwelling times, particularly in the event on longer closures (of course, where the airport is not evacuated because of the disruption). However, the airport also has incentives to improve the quality of relocation in order to prevent substantial damage to future passenger traffic during its peak period, upon which the financial viability of the airport may critically depend. Despite the dominance of LCCs, passengers in holiday markets such as the ones investigated in this study tend to travel with the maximum of their baggage allowance. Therefore, the implementation in baggage transfer protocols among the disrupted airlines in a context of shared capacity is an important aspect. In the absence of said collaboration, our estimates on the hourly relocation rates per airline suggest that the airport should be prepared to accommodate a large number of passengers within the terminal, particularly in the first 24 hours after the flights resume. The introduction of a system to separate the passengers to be immediately relocated (and mixed with the new passenger departures) from those with longer waiting times is also advised. While our case study refers to an island airport with no alternate airports reachable by road or rail, in other instances, (e.g., Sicily, Cyprus) additional efforts to facilitate ground transfers should be implemented.

From the point of view of local tourism authorities, we recall the suggestion from Ritchie (2008), who prompts destination management organizations to assist stakeholders in developing crisis management plans, with explicit knowledge of the effects, barriers and facilitating factors in relation to the implementation of these plans. We aim to provide intelligence on some of these factors, including the impact of multi-party cooperation in reducing passenger delays and airlines' incentives to take part in these agreements. Another contribution of this paper is to illustrate how airports and airlines at tourist destinations do not operate in isolation from larger-scale air transport networks, and even those do not operate in isolation from other transport modes. Therefore, the process of resilience planning transcends the national boundaries of the destination airport and needs to include other stakeholders, such as airports and rail operators from the main passenger markets, which can greatly improve the speed of recovery. Indeed, we show how air/rail combinations can offer a minimum-delay alternative for stranded passengers due to the shortage of airline seat capacity to travel to their final destinations. In view of recent events, we suggest the development of a European-wide framework for air transport resilience planning with a particular focus on those countries with substantial outbound traffic to tourism destinations in the Mediterranean. Moreover, in anticipation of possible differences in the quality of relocation across the main geographical markets served at the airport, engaging with the relevant country's media is advised to help contextualize the challenges faced by airports and airlines. Following the recommendation from Tsai and Chen (2010), public authorities should aim to shine a light on cases of good management performance (particularly selling the ideas of collaboration between the actors involved) to help build confidence about the destination.

Finally, it is worth commenting on the relevance of our methodology to other European tourist destinations, particularly in view of the simplified approach to passenger relocation forced by insularity and the lack of either alternative airports or ground transport options. While every airport is unique in its location, scale of operations, airline and destination mixes, there are fundamental similarities that indicate that our proposed method can be adapted to other case studies. For example, the closure of the only airports in the islands of Crete (Heraklion), Rhodes, Malta, Ibiza, Menorca, and the Canary Islands (except Tenerife) would present passengers and airlines with a similar challenge to PMI. In addition, multiairport islands are vulnerable to multi-airport closures. In the case of Corsica, with four major 
commercial airports, we can mention the strike by Air France and Corse Mediterranée in 2007, which paralyzed air traffic to/from the island (Europa Press, 2007). Other European islands, such as Tenerife and Cyprus, have the particularity that all their airports are operated by the same company. Therefore, the possibility of a multi-airport industrial action that paralyzes all air traffic cannot be discounted. Additionally, since the provision of ATC services is commonly handled at a nationwide level in Europe, ATC strikes typically affect more than one airport (if not all) in the same country, thus also reducing the recovery options in these cases. Another possibility, in the event of a terrorist attack, is that all airports and seaports in an island destination are closed in order to have the perpetrators "caged in", as occurred at PMI in 2009. While very rare in the Mediterranean islands, multi-airport closures can also be correlated for weather reasons. This factor could make a weather-related closure at Keflavik (Iceland) comparable, in terms of lack of transport alternatives, to our PMI case.

\section{SUMMARY, LIMITATIONS, AND FUTURE RESEARCH}

Recent years have witnessed a number of events (weather-related, industrial actions, or terrorism) that have affected the robustness of air transport services, leading to airport closures and flight cancellations that have left air travelers in general (and holidaymakers in particular) stranded at major airports. However, to date, there is no study in the tourism crisis management literature that analyzes the passenger recovery process in the event of an airport closure at a major tourist destination and its implications in terms of speed of recovery, fairness, resilience, and multi-party collaboration. To fill this gap, a case study of Palma de Mallorca Airport, the busiest tourism-oriented island airport in Europe, is presented. Using an MIDT dataset on passenger itineraries that included flights in August 2014, several closure scenarios are simulated, and disrupted passengers are relocated to minimum-delay itineraries. Average departure delays and relocation rates are used to assess the impact of each scenario, with a particular focus on the UK and Germany markets.

The results provide useful benchmarks for the development of policies aimed at minimizing the impact on stranded tourists. From a cost perspective, it is clear that airlines face a clear tradeoff between reimbursement and care/rerouting costs. Therefore, airlines with higher fares (e.g., full-service) will have a greater incentive than low-fare carriers to implement measures that improve the relocation rate. In that regard, if airlines allow relocation itineraries involving at least one flight connection, rather than employing only non-stop recovery options, relocation rates are shown to improve, on average, between 5\% and 30\% and reduce average passenger delays up to 6 hours. In medium- and full-day closures (more than 5 hours), the lack of seat capacity makes interline cooperation necessary to achieve nonrelocation rates below $16 \%$. In terms of departure delays, the benefits of cooperation are highest for medium-length closures (between 5-6 hours) due to capacity constraints. We also show that all affected airlines can benefit from collaboration and contribute seats simultaneously, which suggests that they will have incentives to participate in such a plan. A detailed analysis of how passenger flows are redistributed throughout the European air transport network reveals the airports where airlines should direct their investment in resilience plans due to their central location within the shortest path lengths between PMI and its major destinations. In a scenario of full airline collaboration, investments should be directed at major European hubs (such as Heathrow or Frankfurt) that allow good onward connectivity via air, rail, or road. A second-stage regression reveals significant differences in the performance of full-service vs LCCs in terms of departure delays, which also depend on the geographic market. LCCs serving UK markets have a worse recovery performance than their German counterparts. German passengers tend to benefit more from indirect relocation, interlining, and additional capacity than UK passengers. Looking at full-day closures, 
German markets recover more passengers under inline recovery, though the country differences are reduced after cooperation is allowed.

These results have many policy and managerial implications. From the point of view of airlines, the improvement in the quality of relocation will reduce the likelihood of negative word-of-mouth being generated and increase the loyalty of the disrupted passengers. From the airport perspective, the implementation of baggage transfer protocols among the disrupted airlines in a context of shared capacity is an important aspect. Separating the passengers to be immediately relocated from those with longer waiting times is also advised. Furthermore, this paper suggests that local tourism authorities must engage as facilitators between all stakeholders to develop appropriate resilience plans, with the ultimate goal to protect the image of the destination for the future. The process of planning and negotiation, however, transcends the national boundaries of the destination airport and needs to include other stakeholders, such as airports and rail operators from the main passenger markets, which can greatly improve the speed of recovery. In view of recent events, we suggest the development of a European-wide framework for air transport resilience planning with a particular focus on countries with substantial outbound traffic to tourism destinations in the Mediterranean.

Finally, it is important to acknowledge the limitations of our model, particularly in regards to the implementation of additional service recovery measures by airlines, such as delaying flights in the case of shorter closures. Aircraft and crew recovery decisions that take into account maintenance and labor rules restrictions could also be included by adapting the methods suggested by the operations research literature. Future work could also introduce a set of criteria to prioritize different options of passenger recovery across layers (e.g., the airline, alliances, interline partners, other airlines) in order to model the passenger rescheduling process in a more realistic fashion. This can be achieved by incorporating the published IROPS (Irregular Operations) guidelines for the major carriers into the rescheduling algorithm. Furthermore, the analysis of intermodal connections can be expanded with the addition of rail schedules and capacities at a European level. With enough information on passenger preferences, we could also improve our algorithm by introducing the maximum acceptable delays per passenger type (depending on, e.g., travel distance, destination type, and booking class), beyond which rerouting will be rejected and reimbursement will be sought, with the objective to bring our simulations closer to real-world passenger decision-making. Finally, further research could simulate a number of case studies covering the tourist airports in the Mediterranean region and develop a ranking of airport, airline, and route criticality to guide strategic decision-making in the area of tourism crisis management.

\section{ACKNOWLEDGEMENTS}

The authors are grateful to the editor and two anonymous reviewers for their helpful comments. This research project has been partly funded by the University of Edinburgh Business School through the Early Venture Fund program. The authors would also like to thank the support of the Business School IT department in running the simulations.

\section{REFERENCES}

Abdelghany, K., Abdelghany, A., and Ekollu, G., 2008. An integrated decision support tool for airlines schedule recovery during irregular operations. European Journal of Operational Research 185 (2), 825-848.

AEA, 2014. European Passenger Traffic Growth 4.8\% in August 2014. http://planestats.com/aea 2014aug

AIAA, 2015. Overcoming flight disruptions by cooperating. Aviation Forum Denver June 2017. http://www.aiaa-aviation.org/Notebook.aspx?id=28683

Akamavi, R., Mohamed, E., Pellmann, K., and Xu, Y., 2015. Key determinants of passenger loyalty in the lowcost airline business. Tourism Management 46, 528-545. 
Allan, S., Beesley, A., Evans, E., and Gaddy, S., 2001. Analysis of delay causality at Newark international airport, 4th USA/Europe Air Traffic Management RandD Seminar, Santa Fe, USA.

Bamford, D., and Xystouri, T., 2005. A case study of service failure and recovery within an international airline. Managing Service Quality, 15(3), 306-322.

Barnhart, C., 2009. Irregular Operations: Schedule Recovery and Robustness, in The Global Airline Industry (eds P. Belobaba, A. Odoni and C. Barnhart), John Wiley and Sons, Ltd, Chichester, UK.

BBC, 2010. Snow at Heathrow and Gatwick ruins plans of thousands. 19/12/2010.

BBC, 2015a. Bali travellers stranded as volcano closes airports. 10/07/2015.

BBC, 2015b. Russian plane crash: Flying Britons home from Sharm el-Sheikh 'will take time'. 05/11/2015

BBC, 2016. Ryanair and EasyJet urge action over French strike. 21/03/2016.

Berdica, K., 2002. An introduction to road vulnerability: what has been done, is done and should be done. Transport Policy 9, 117-127.

Bratu, S., and Barnhart, C., 2006. Flight operations recovery: New approaches considering passenger recovery. Journal of Scheduling 9 (3), 279-298.

Breitsohl, J., and Garrod, B., 2016. Assessing tourists' cognitive, emotional and behavioural reactions to an unethical destination incident. Tourism Management 54, 209-220.

Burghouwt, G., 2016. Airline Network Development in Europe and its Implications for Airport Planning. Routledge.

Cardillo, A., Zanin, M., Gómez-Gardeñez, J., Romance, M., Garcia del Amo, A., and Boccaletti, S., 2013. Modeling the multi-layer nature of the European Air Transport Network: Resilience and passengers rescheduling under random failures. Eur. Phys. J. Special Topics 215, 23-33.

Cheng, J., Chen, F., and Chang, Y., 2008. Airline relationship quality: an examination of Taiwanese passengers. Tourism Management, 29(3), 487-499.

Ciocco, L., and Michael, E., 2007. Hazard or disaster: Tourism management for the inevitable in Northeast Victoria. Tourism Management, 28,1-11.

CNN, 2016. Healing after terror: Brussels Airport departure lounge reopens. CNN.com. May 1, 2016

Colliers, 2016. MENA Hotel Forecasts Feb-Apr 2016. www.colliers.com

Csardi, G, and Nepusz T., 2006. The igraph software package for complex network research, InterJournal, Complex Systems 1695. http://igraph.org

Daily Mail, 2016. 100 holidaymakers are hit with 36-hour flight delay after 'technical fault' is discovered on BA plane flying back to the UK from Cyprus. 02/08/2016.

D'Este, G., and Taylor, M., 2003. Network vulnerability: an approach to reliability analysis at the level of national strategic transport networks. Proceedings of the 1st International Symposium on Transportation Network Reliability (INSTR), 23-44.

De-Los-Santos, A., Laporte, G., Mesa, J., and Perea, F., 2012. Evaluating passenger robustness in a rail transit network. Transportation Research Part C 20, 34-46.

Del Chiappa, G., Martín, J., and Roman, C., 2016. Service quality of airports' food and beverage retailers: A fuzzy approach. Journal of Air Transport Management 53, 105-113.

De Wit, J., and Zuidberg, J., 2016. Route churn: an analysis of low-cost carrier route continuity in Europe. Journal of Transport Geography 50, 57-67.

Diario de Mallorca, 2016. Cancelados 28 vuelos en Palma y 1 en Ibiza por la huelga de controladores en Francia. 21/03/2016.

Dobruszkes, F., 2006. An analysis of European low-cost airlines and their networks. Journal of Transport Geography, 14, 249-264.

Dobruszkes, F., 2013. The geography of European low-cost airline networks: a contemporary analysis. Journal of Transport Geography 28, 75-88.

Doganis, R., 2006. The airline business in the 21 st Century (2nd ed.). London, Routledge.

EC, 2007. Competition impact of airline code-share agreements. European Commission. Final Report. Janurary 2007. http://ec.europa.eu/competition/sectors/transport/reports/airlinecodeshare.pdf

EC, 2008. Answers to Questions on the application of Regulation 261/2004. European Commission. 17/02/2008 EC, 2014. Horizon 2020 Work Programme in the area of Transport. European Commission.

El País, 2009. Reabierto el aeropuerto de Palma de Mallorca tras el atentado. 30/07/2019

El País, 2010. Casi 5.000 vuelos anulados y 700.000 afectados en el puente más largo. 09/12/2010

El País, 2016. Fomento abre expediente a Vueling por el caos en el aeropuerto de Barcelona. 04/07/2016

Eurocontrol, 2007. A place to stand: airports in the European air network. Eurocontrol Trends Air Traffic 3.

Europa Press, 2007. Huelgas en el aeropuerto y manifestantes independentistas durante la visita de Sarkozy a Córcega. 31/10/2007

Graham, A., 2013. Understanding the low cost carrier and airport relationship: A critical analysis of the salient issues. Tourism Management 36, 66-76. 
Grosche, T., 2009. Computational Intelligence in Integrated Airline Scheduling. Studies in Computation Intelligence 173. Springer-Verlag Berlin Heidelberg.

Gunn, C., 1988. Tourism Planning. Taylor and Francis, New York.

Heathrow Airport, 2014. Taking Britain Further. http://www.heathrow.com/britainsheathrow

Hossain, M., Alam, S. Rees, T., and Abbass, H. 2013. Australian Airport Network Robustness Analysis: A Complex Network Approach. Australasian Transport Research Forum 2013 Proceedings 2 - 4 October 2013, Brisbane, Australia

ICAO, 2013. Global Air Transport Outlook to 2030 and trends to 2040 (Circular 333). International Civil Aviation Organization. http://www.icao.int

Janic, M., 2005. Modeling the large scale disruptions of an airline network. Journal of Transportation Engineering, 131 (4), 249-260.

Janic. M., 2015. Modeling the resilience, friability and costs of an air transport network affected by a large-scale disruptive event. Transportation Research Part A: Policy and Practice 71 (1), 1-16.

Jenelius, E., Petersen, T., and Mattsson, L., 2006. Importance and exposure in road network vulnerability analysis. Transportation Research Part A 40, 537-560.

Khadaroo, J., and Seetanah, B., 2008. The role of transport infrastructure in international tourism development: A gravity model approach. Tourism Management 29 (5), 831-840.

Kohl, N., Larsen, A., Larsen, J., Ross, A., and Tiourine, S., 2007. Airline disruption management-Perspectives, experiences and outlook. Journal of Air Transport Management 13 (3), 149-162.

Lehto, X., Douglas, A., and Park, J., 2008. Mediating the effects of natural disasters on travel intention. Journal of Travel and Tourism Marketing, 23(2-4), 29-43.

Lettovsky, L., Johnson, E., and Nemhauser, G., 2000. Airline crew recovery. Transportation Science 34 (4), 337-348.

Lindenmeier, J., and Tscheulin, K. D., 2008. The effects of inventory control and denied boarding on customer satisfaction: the case of capacity-based airline revenue management. Tourism Management, 29, 32-43.

Lordan, O., Sallan, J., and Simo, P., 2014a. Study of the topology and robustness of airline route networks from the complex network approach: A survey and research agenda. Journal of Transport Geography 37, 112-120.

Lordan, O., Sallan, J.M., Simo, P., and Gonzalez-Prieto, D., 2014b. Robustness of the air transport network. Transportation Research Part E: Logistics and Transportation Review 68, 155-163.

Lordan, O., Sallan, J., Simo, P., and Gonzalez-Prieto, D., 2015. Robustness of airline alliance route networks. Communications in Nonlinear Science and Numerical Simulation 22, 587-595.

Lordan, O., Sallan, J., Escorihuela, N., and Gonzalez-Prieto, D., 2016. Robustness of airline route networks. Physica A 445, 18-26.

Maher, S., 2015. A novel passenger recovery approach for the integrated airline recovery problem. Computers and Operations Research 57, 123-137.

Mair, J., Ritchie, B., and Walters, G., 2016. Towards a research agenda for post-disaster and post-crisis recovery strategies for tourist destinations: a narrative review. Current Issues in Tourism 19, 1-26.

Mattsson, L., and Jenelius, E., 2015. Vulnerability and resilience of transport systems - A discussion of recent research. Transportation Research Part A 81, 16-34.

Mazzocchi, M., Hansstein, F., and Ragona, M., 2010. The 2010 Volcanic Ash Cloud and Its Financial Impact on the European Airline Industry. CESifo Forum No. 2: 92-100.

Mo, C., Howard, D., and Havitz, M., 1993. Testing an international tourist role typology. Annals of Tourism Research 20 (2), 319-335.

Nibkin, D., Hyun, S., Iranmanesh, M., Maghsoudi, A., and Jeong, C., 2015. Airline Travelers' Causal Attribution of Service Failure and Its Impact on Trust and Loyalty Formation: The Moderating Role of Corporate Social Responsibility. Asia Pacific Journal of Tourism Research 21 (4), 355-374.

Niininen, O., and Gatsou, M., 2008. Crisis management. Journal of Travel and Tourism Marketing, 23 (2-4), 191-202.

NYT, 2016. Istanbul Airport Attack Leaves at Least 41 Dead. 28/06/2016.

Petersen, J., Sölveling, G., Clarke, J., Johnson, E., and Shebalov, S., 2012. An optimization approach to airline integrated recovery. Transportation Science 46 (4), 482-500.

Rendeiro. R., 2006. Tourism service quality begins at the airport. Tourism Management 27 (5), 874-877.

Rey, B., Myro, R., Galera, A., 2011. Effect of low-cost airlines on tourism in Spain. A dynamic panel data model. Journal of Air Transport Management 17 (3), 163-167.

Ritchie, B., 2008. Tourism disaster planning and management: From response and recovery to reduction and readiness. Current Issues in Tourism 11(4), 315-348.

Rodríguez-Núñez, E., and García-Palomares, J., 2014. Measuring the vulnerability of public transport networks. Journal of Transport Geography 35, 50-63.

Rose, A., 2007. Economic resilience to natural and man-made disasters: multidisciplinary origins and contextual dimensions. Environmental Hazards 7 (4), 383-398. 
Rtve.es, 2010. Huelga de los controladores, así hemos contado la primera jornada. Rtve.es. 04/12/2010.

Ruggieri, G., 2015. Islands tourism seasonality. In H. Pechlaner, E. Smeral (Eds.), Tourism and Leisure, Springer, Wiesbaden.

Rupp, N., Holmes, G., and DeSimone, J., 2005. Airline Schedule Recovery after Airport Closures: Empirical Evidence since September 11. Southern Economic Journal 71 (4), 800-820.

Schaefer, L., and Millner, D., 2001. Flight delay propagation analysis with the detailed policy assessment tool. Proceedings of the 2001 IEEE Systems, Man and Cybernetics Conference, Tucson, USA

Schavell, A., 2000. The effects of schedule disruptions on the economics of airline operations. 3rd USA/Europe Air Traffic Management RandD Seminar, Napoli, Italy.

Scott, N., and Laws, E., 2008. Tourism crises and disasters: Enhancing g understanding of system effects. Journal of Travel and Tourism Marketing, 19 (2-3), 149-158.

Seredyński, A., Rothlauf, F., and Grosche, T., 2014. An airline connection builder using maximum connection lag with greedy parameter selection. Journal of Air Transport Management 36, 120-128.

START : National Consortium for the Study of Terrorism and Responses to Terrorism, 2016. Global Terrorism Database [Data file]. Retrieved from https:/www.start.umd.edu/gtd

Suau-Sanchez, P., Voltes-Dorta, A., and Rodríguez-Déniz, H., 2014. The role of London airports in providing connectivity for the UK: Regional dependence on foreign hubs. Journal of Transport Geography. DOI: dx.doi.org/10.1016/j.jtrangeo.2014.11.008

Suau-Sanchez, P., Voltes-Dorta, A., and Rodríguez-Déniz, H., 2015. Regulatory Airport classification in the US: The role of international markets. Transport Policy 37, 157-166.

The Guardian, 2015. Stranded tourists turn on UK ambassador at Sharm el-Sheikh airport. 06/11/2015.

Tsai, C., and Chen, C., 2010. An earthquake disaster management mechanism based on risk assessment information for the tourism industry-a case study from the island of Taiwan. Tourism Management, 31(4), 470-481.

Walters, G., and Clulow, V., 2010. The tourism market's response to the 2009 black Saturday bushfires: The case of Gippsland. Journal of Travel and Tourism Marketing, 27(8), 844-857.

Wang, D., 2007. Methods for analysis of passenger trip performance in a complex networked transportation system. PhD Thesis. George Mason University. Summer 2007.

Wattanacharoensil, W., Schuckert, M., and Graham, A., 2015. An Airport Experience Framework from a Tourism Perspective. Transport Reviews 36 (3), 318-340.

Weber, K., and Sparks, B., 2004. Consumer attributions and behavioral responses to service failures in strategic airline alliance settings. Journal of Air Transport Management 10 (5), 361-367.

$\mathrm{Xu}, \mathrm{J}$., and Grunewald, A., 2009. What have we learned? A critical review of tourism disaster management. Journal of China Tourism Research, 5(1), 102-130.

Yan, S., and Lin, C., 1997. Airline scheduling for the temporary closure of airports. Transportation Science, 31 (1), $72-82$.

Zhang, X., Miller-Hooks, E., and Denny, K. 2015. Assessing the role of network topology in transportation network Resilience. Journal of Transport Geography 46, 35-45. 
APPENDIX A. Complete interline relocation matrix in Scenario 18

\begin{tabular}{|c|c|c|c|c|c|c|c|c|c|c|c|c|c|c|c|c|c|c|c|c|c|c|c|c|c|c|c|c|c|c|c|c|c|c|c|c|c|}
\hline & $\begin{array}{l}\text { Relocated } \\
\text { airline }\end{array}$ & 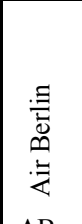 & $\stackrel{b 0}{\Xi}$ & $\begin{array}{l}\text { 䓌 } \\
\stackrel{\widetilde{\Xi}}{\widetilde{\Omega}}\end{array}$ & 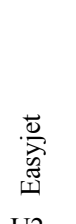 & 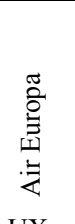 & $\begin{array}{l}\overrightarrow{0} \\
\overrightarrow{0}\end{array}$ & 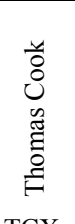 & 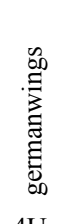 & $\stackrel{2}{S^{2}}$ & $\bar{z}$ & 劳 & $\begin{array}{l}\text { 范 } \\
\tilde{\Xi} \\
\sum_{\Sigma}\end{array}$ & 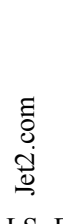 & 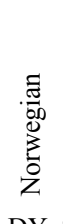 & 出 & $\begin{array}{l} \\
\tilde{0} \\
0 \\
\bar{\Xi} \\
\equiv\end{array}$ & 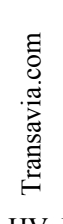 & 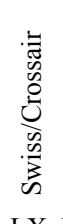 & 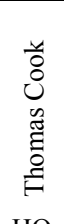 & 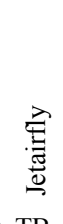 & . & 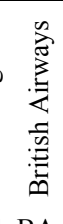 & 莓 & 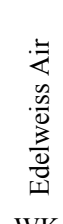 & $\begin{array}{l}0 \\
0 \\
:\end{array}$ & 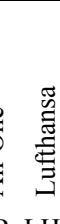 & & 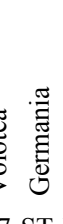 & $\underset{\frac{D}{2}}{\stackrel{D}{2}}$ & 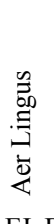 & 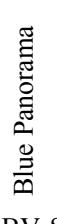 & & & 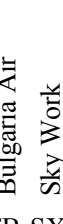 & $\sum_{\Xi}$ & \\
\hline airline & Code & $\mathrm{AB}$ & VY & FR & U2 & UX & $\mathrm{DE}$ & TCX & $4 \mathrm{U}$ & $\mathrm{X} 3 \mathrm{H}$ & HG & IB Z & ZB I & LS I & DY & SK T & TOM & HV & LX & HQ & $\mathrm{TB}$ & QS & BA & LG & WK & $\mathrm{K}$ AP & LH & H V7 & $7 \mathrm{ST}$ & BE $\mathrm{E}$ & EI $\mathrm{H}$ & $\mathrm{BV} s$ & SN W & N6 FF & & $\mathrm{KL}$ & Total \\
\hline Air Berlin & $\mathrm{AB}$ & 2,757 & 676 & 375 & 137 & 193 & 810 & & 514 & 400 & 130 & 163 & 50 & & 74 & 40 & 62 & 57 & 159 & 147 & $\begin{array}{l}7 \quad 47 \\
\end{array}$ & 7104 & 1 & 3 & 96 & $\begin{array}{ll}6 & 37 \\
\end{array}$ & $\begin{array}{lll}7 & 3 \\
\end{array}$ & 37 & 98 & & & & 27 & & & 6 & 7,200 \\
\hline Ryanair & FR & 781 & 249 & 259 & 318 & 179 & 39 & 300 & 117 & 35 & 1191 & 1372 & 2171 & 192 & 164 & 99 & 62 & 159 & 9 & & 6 & \begin{tabular}{l|l}
6 & 14 \\
\end{tabular} & 4150 & 18 & & 5 & 5 & 3 & & & & & & \begin{tabular}{l|l}
14 & 1
\end{tabular} & 13 & & 3,658 \\
\hline Easyjet & U2 & 234 & 189 & 325 & 442 & 219 & 3 & 399 & 85 & 11 & 51 & 621 & 1451 & 197 & 34 & 71 & 32 & & & & & 3 & 3 & & 21 & 1 & & & & 30 & 35 & 48 & & & 10 & & 2,649 \\
\hline germanwings & $4 \mathrm{U}$ & 824 & 81 & 44 & 7 & 68 & 82 & & 132 & 140 & 91 & & & & & 17 & & 2 & 5 & & & 4 & & 34 & & & 1 & 16 & & & & & & & & & 1,547 \\
\hline Jet2.com & LS & 177 & 210 & 276 & 129 & 234 & & 5 & & & & 186 & 491 & 116 & & & 15 & & & 30 & & & & & & 55 & & & & & 20 & & & & & & 1,506 \\
\hline Condor & $\mathrm{DE}$ & 374 & 79 & 43 & 131 & 89 & 20 & 123 & 136 & 88 & 7 & & 65 & 21 & 90 & & 74 & & 55 & $5 \quad 26$ & & & 7 & & & & 1 & 19 & & & & & & & & & 1,447 \\
\hline TUIfly & $\mathrm{X} 3$ & 233 & 135 & 43 & 70 & 26 & 198 & 97 & 34 & 109 & 57 & 5 & 10 & & & & 22 & & & & 70 & & & 49 & & & & & & & & & & & & & 1,158 \\
\hline Monarch & ZB & 21 & 66 & 62 & 23 & 109 & & 26 & 11 & & & 30 & 91 & 69 & & & 102 & & 12 & & & & & & & 31 & & & & 20 & & & & & & & 673 \\
\hline Vueling & VY & 53 & 232 & 12 & 28 & 18 & & & 35 & 20 & 7 & 45 & 63 & & 11 & 10 & & & 8 & & & & & & & & 1 & 19 & 3 & & 2 & 2 & & 2 & & & 570 \\
\hline NIKI & HG & 26 & 15 & & 14 & & 125 & & & & 360 & 28 & & & & & & & & & & & & & & & & & & & & & & & & & 568 \\
\hline Thomas Cook & TCX & 81 & 18 & 42 & 85 & 32 & & 92 & & & & & 9 & 53 & 4 & & & & & & & & & & & & & & & & & & & & & & 416 \\
\hline Germania & ST & 57 & 31 & 46 & 37 & 6 & 46 & & 38 & & & 70 & 30 & & 17 & & & & & & & & & & & & 1 & 13 & & & & & & & & & 391 \\
\hline Norwegian & DY & & 57 & & & & & 28 & 1 & & & & & 1 & 71 & 148 & & & & & & & & & & & & & & & & & & & & & 306 \\
\hline Lufthansa & LH & 147 & & 28 & 7 & 4 & 10 & & & & 2 & 18 & & & & 3 & & 27 & & & & & & & & & & & & & & & & & & & 246 \\
\hline Transavia.com & $\mathrm{HV}$ & 55 & 19 & 16 & 67 & 3 & & 54 & & & & & 13 & & & & & & & 1 & & & & & & & & & & & & & & & & & 228 \\
\hline SAS & SK & 17 & & 5 & & 66 & & & 18 & & & & & & 99 & & & & & 13 & & & & & & & & & & & & & & & & & 218 \\
\hline Thomas Cook & HQ & & 62 & 10 & & & & & 3 & & & & & & & & & & & & 72 & & & 57 & & & & & & & & & & & & & 204 \\
\hline Iberia & IB & 12 & 48 & 37 & 4 & 37 & & 1 & 13 & 1 & & 17 & 4 & 3 & & & & 1 & & & & & & & 9 & 9 & & 8 & 1 & & & & & & & & 200 \\
\hline British Airways & BA & 53 & & 36 & 3 & & & 20 & & & & & & 5 & & 60 & & & & & & & & 2 & & & & & & & & & & & & & 179 \\
\hline Swiss/Crossair & LX & 40 & 91 & & 4 & & & & & 27 & & & & & & 4 & & & & & & & & & & & & & & & & & & & & & 166 \\
\hline Air Europa & UX & & 16 & 73 & 11 & 10 & 3 & & 2 & & & 9 & & 1 & 2 & & & & & & 1 & 1 & 3 & & 19 & 9 & & \begin{tabular}{l|l}
2 & 1 \\
\end{tabular} & 1 & & 4 & 1 & & & & 1 & 160 \\
\hline Flybe & $\mathrm{BE}$ & 20 & & 30 & 6 & 16 & & & & & & 15 & & & & & & & & & & & & & & & & 31 & & 21 & & & & & & & 139 \\
\hline Luxair & LG & 39 & 52 & 12 & & 25 & & & & & & 4 & & & & & & & & & & & & & & & & & & & & & & & & & 132 \\
\hline Volotea & V7 & & & 15 & & & & & & & & 14 & & & & & & & & & & & & & & & & 64 & & & & & & & & & 93 \\
\hline Edelweiss Air & WK & 47 & & & 13 & 12 & & & & & & & & & & & & & & & & & & & & & & & & & & & & & & & 72 \\
\hline SmartWings & QS & 5 & 1 & & & & & & & & & & & & & & & & & & & 64 & & & & & & & & & & & & & & & 70 \\
\hline Jetairfly & TB & & & & & & & & & & & & & & & & & 35 & & & & & & & & & & & & & & & & & & & 35 \\
\hline \multirow[t]{2}{*}{ Sky Work } & SX & 3 & & & & & & & & & & & & & & 17 & & & & & & & & & & & & & & & & & & & & & 20 \\
\hline & Total & 6,056 & 2,327 & 1,789 & 1,536 & 1,346 & 1,336 & 1,145 & 1,139 & & 8248 & 8037 & 7466 & 658 & 5662 & 469 & 3692 & 281 & 248 & 217 & 7196 & 6189 & 9164 & 4163 & $\begin{array}{ll}3 & 145 \\
\end{array}$ & & & & & 718 & 61 & 51 & & $\begin{array}{ll}161 \\
\end{array}$ & & & 24,249 \\
\hline
\end{tabular}


2016-09-14

\section{Passenger recovery after an airport closure at tourist destinations: A case study of Palma de Mallorca airport}

\section{Voltes-Dorta, Augusto}

\section{Elsevier}

Suau-Sanchez P, Rodríguez-Deniz H, Voltes-Dorta A. (2017) Passenger recovery after an airport closure at tourist destinations: A case study of Palma de Mallorca airport, Tourism Management, Volume 59, April 2017, pages 449-466

http://dx.doi.org/10.1016/j.tourman.2016.09.001

Downloaded from Cranfield Library Services E-Repository 